\title{
Diagnóstico dos resíduos de serviço de saúde gerados em uma unidade básica de saúde, à luz da resolução ANVISA - RDC № 222/2018
}

\author{
Livania Santos Silva \\ Instituto Federal de Educação, Ciência e Tecnologia do Rio Grande do Sul (IFRS) - Campus Porto Alegre \\ (livania88@gmail.com) \\ Magali Silva Rodrigues \\ Instituto Federal de Educação, Ciência e Tecnologia do Rio Grande do Sul (IFRS) - Campus Porto Alegre \\ (magali.rodrigues@poa.ifrs.edu.br)
}

\begin{abstract}
Resumo: O presente trabalho foi realizado em uma Unidade Básica de Saúde com Estratégia da Família (UBS/ESF), localizada no município de Esteio/RS. E teve como objetivo elaborar um diagnóstico dos Resíduos de Serviços de Saúde, gerados nesta Unidade e propor adequações, considerando as novas exigências estabelecidas pela Resolução da Diretoria Colegiada da Anvisa RDC № 222/2018, para que se possa pôr em prática o correto gerenciamento dos resíduos gerados na Unidade. A partir do estudo, verificou-se que o setor da Unidade que mais gera resíduo é o setor de enfermagem, sendo este resíduo caracterizado como resíduo infectante (Grupo A). Verificou-se também que o gerenciamento desses resíduos é efetuado de forma incorreta, pois a Unidade não possui um plano efetivo de gerenciamento de resíduos de serviço de saúde (PGRSS), conforme determina o Art. $5^{\circ}$ da RDC № 222/2018, referente à obrigatoriedade do plano para todos os serviços geradores de RSS. Espera-se com este trabalho, que a UBS/ESF se enquadre nas exigências estabelecidas pela Resolução RDC № 222/2018, com vistas à minimização dos impactos ambientais relacionados ao gerenciamento incorreto dos resíduos e à melhoria das condições de trabalho das equipes de saúde.
\end{abstract}

Palavras-chaves: Resíduos de Serviço de Saúde, Unidade Básica de Saúde, Gestão de resíduos, Legislação Ambiental.

Diagnosis of health care residues generated in a basic health unit, in the light of the resolution of the ANVISA - RDC № 222/2018

\begin{abstract}
The present work was carried out in a Basic Health Unit with Family Strategy (UBS / ESF), located in the city of Esteio / RS. The purpose of this study was to prepare a diagnosis of the Residues of Health Services generated in this Unit and to propose adjustments considering the new requirements established by Resolution RDC No. 222/2018, the main purpose of this study, so that the Unit can put into practice the correct management of waste generated on site. From the study, it was verified that the sector that generates the most residue is the nursing sector, being this residue characterized as infecting residue (Group A). It was also verified that the management of this waste is carried out incorrectly, since the Unit does not have an effective health service waste management plan (PGRSS), as determined by Art. 5 of RDC No. 222/2018, as an obligation of the plan for all the services generating RSS. It is hoped that the UBS / ESF will meet the requirements established by Resolution RDC No. $222 / 2018$, with a view to minimizing the environmental impacts related to the incorrect management of waste and improving the working conditions of the health teams.
\end{abstract}

Keywords: Medical waste management (MWM), Environmental Regulations, Public Health Clinics. 


\section{INTRODUÇÃO}

No Brasil, são produzidos todos os dias 149 mil toneladas de resíduos sólidos, sendo desses, cerca de 2.980 toneladas de resíduos do serviço de saúde (RSS), fazendo-se necessário um manejo correto para garantir a saúde dos trabalhadores e a proteção ao meio ambiente dos passivos ambientais. O manejo dos resíduos do serviço de saúde implica no seu manuseio, passando pelas etapas de segregação até a disposição final ambientalmente adequada (SILVA; RODRIGUES, 2017).

Alguns órgãos, como a Agência Nacional de Vigilância Sanitária (ANVISA) e o Conselho Nacional do Meio Ambiente (CONAMA), são responsáveis no País, por orientar, definir normas e regular a conduta dos diferentes agentes, atribuindo regras à geração e ao manejo dos resíduos de serviços de saúde, com o propósito de preservar a saúde e o meio ambiente, garantindo a sua sustentabilidade (SOUZA et al., 2006).

O manejo incorreto dos RSS pode provocar uma ameaça, à saúde dos trabalhadores, pois esses podem se expor a acidentes de trabalho, assim como danos irreversíveis ao meio ambiente. Dependendo do fluxo do local de trabalho, por um equívoco ou até por falta de treinamento dos funcionários, os resíduos perigosos, sejam biológicos (potencialmente infectantes), químicos ou perfurocortantes, podem encontrar-se misturados com os resíduos comuns, tornando esses perigosos (TAKADA, 2003). Deve exigir-se, assim, um cuidado redobrado dos profissionais que manipulam estes resíduos.

Conforme mencionado pela norma brasileira da Associação Brasileira de Normas Técnicas ABNT NBR 12809/2013, todos os trabalhadores em serviços de saúde devem ser capacitados para segregar corretamente os resíduos e conhecer os sistemas de classificação e identificação. Estes, também, devem gerenciar os resíduos, de acordo com os riscos preponderantes (ABNT, 2013).

Recentemente, a Resolução da Diretoria Colegiada da ANVISA - RDC № 306/2004, que tratava sobre o "Regulamento Técnico para o Gerenciamento de Resíduos de Serviços de Saúde" (BRASIL, 2004) foi revogada, sendo substituída pela Resolução da Diretoria Colegiada da ANVISA - RDC № 222/2018, que determina os requisitos de "Boas Práticas de Gerenciamento dos Resíduos de Serviços de Saúde" 
(BRASIL, 2018-B), visando, assim, minimizar os riscos pertinentes ao gerenciamento de resíduos no País.

De acordo com a RDC № 222/2018, os geradores de Resíduos de Serviços de Saúde são todos os serviços dos quais as atividades estejam associadas com a saúde humana ou animal, incluindo os serviços de assistência domiciliar; laboratórios analíticos de produtos para saúde; necrotérios, funerárias e serviços que realizem atividades de embalsamamento (tanatopraxia e somatoconservação); serviços de medicina legal, drogarias e farmácias, inclusive as de manipulação; estabelecimentos de ensino e pesquisa na área de saúde; centros de controle de zoonoses; distribuidores de produtos farmacêuticos, importadores, distribuidores de materiais e controles para diagnóstico in vitro; unidades móveis de atendimento à saúde; serviços de acupuntura; serviços de piercing e tatuagem, salões de beleza e estética, e outros afins, independente da esfera administrativa, sendo ela pública ou privada (BRASIL, 2018-B).

Tanto a Resolução da Diretoria Colegiada RDC № 306/2004 (BRASIL, 2004), quanto a Resolução da Diretoria Colegiada RDC № 222/2018 (BRASIL, 2018-B), em seu Anexo I, respectivamente, classificam os diferentes tipos de resíduos gerados nos estabelecimentos de saúde em cinco grupos ( $A, B, C, D$ e E).

O Grupo A (Potencialmente Infectantes) são os resíduos que podem apresentar risco de infecção, devido à presença de possíveis agentes biológicos.

O Grupo B (Químicos) são os resíduos que possuem produtos químicos, apresentando periculosidade à saúde pública ou ao meio ambiente, de acordo com as suas características de inflamabilidade, corrosividade, reatividade, toxicidade, carcinogenicidade, teratogenicidade e mutagenicidade.

O Grupo C (Rejeitos Radioativos) é constituído por qualquer material que contenha radionuclídeo em quantidade superior aos níveis de dispensa especificados em norma do Comissão Nacional de Energia Nuclear (CNEN) e para os quais a reutilização é imprópria ou não prevista. Correspondem também a este grupo, os rejeitos radioativos provenientes de laboratórios de pesquisa e ensino na área da saúde; bem como, laboratórios de análises clínicas, inclusive, serviços de medicina nuclear e radioterapia, segundo Resolução da CNEN e Plano de Proteção Radiológica, aprovado para a instalação radiativa. 
O Grupo D (Resíduos Comuns), são os que não apresentam risco biológico, químico ou radiológico à saúde ou ao meio ambiente, podendo ser comparados com os resíduos domiciliares.

O Grupo E (Resíduos Perfurocortantes) são os materiais que podem ocasionar algum corte ou perfuração.

No ano de 2006, a Agência Nacional de Vigilância Sanitária (BRASIL, 2006), junto com o Ministério do Meio Ambiente (MMA), estabeleceram o documento "Plano de Gerenciamento de Resíduos de Serviços de Saúde (PGRSS)". A elaboração desse documento foi baseada na Resolução da ANVISA RDC № 306/04 (BRASIL, 2004) e na Resolução do Conselho Nacional do Meio Ambiente (CONAMA) № 358/05 (BRASIL, 2005), com o propósito de diminuir a geração e os problemas decorrentes do manejo dos RSS (De PAIVA, 2018).

É importante ressaltar que, de acordo com a RDC № 222/2018, Art. $5^{\circ}$, todo serviço gerador deve possuir o documento "Plano de Gerenciamento de Resíduos de Serviço de Saúde (PGRSS)" e, conforme o $\S 3^{\circ}$ do mesmo artigo, os geradores de resíduos terão prazo de 180 (cento e oitenta) dias, a partir do início do funcionamento, para apresentar o seu Plano de Gerenciamento, observando as regulamentações federais, estaduais, municipais ou do Distrito Federal (BRASIL, 2018-B).

O Plano de Gerenciamento dos Resíduos de Serviços de Saúde é definido como um documento, que indica e descreve as ações relativas ao gerenciamento dos resíduos de serviços de saúde, contemplando aspectos referentes aos-seguintes: Geração, que é o ato de gerar resíduos; Identificação, formado por um conjunto de medidas que possibilita reconhecer os riscos presentes nos resíduos acondicionados; Segregação, que consiste na separação dos resíduos, no momento e local de sua geração, conforme as características físicas; químicas ou biológicas; Acondicionamento, que é o ato de embalar os resíduos separados em sacos ou recipientes que evitem vazamentos e que sejam adequados física e quimicamente ao conteúdo acondicionado; Coleta, que é a remoção dos resíduos, usando técnicas que garantem a preservação das condições de acondicionamento; Armazenamento externo, em um ambiente exclusivo para guardar os coletores de resíduos; Armazenamento temporário, onde permanecem temporariamente os coletores de resíduos do serviço de saúde; Transporte interno, que consiste na transferência 
dos resíduos dos pontos de geração até o local de armazenamento temporário e por fim, Destinação, que pode ser a reutilização, a reciclagem, a compostagem, recuperação e o aproveitamento energético ou outras destinações ambientalmente adequadas (BRASIL, 2018-B).

É importante que o Plano de Gerenciamento de Resíduos seja elaborado de forma eficaz, englobando ações para minimizar os efeitos negativos causados pelos RSS. Dentre as ações podem-se destacar: a caracterização dos resíduos gerados; a classificação dos mesmos de acordo com a legislação vigente e, principalmente, acompanhamento da coleta e do transporte externo. Esses são normalmente, realizados por empresas terceirizadas, mas a responsabilidade pelo resíduo continua sendo do estabelecimento gerador (BRASIL, 2002).

Diante do contexto exposto, a escolha do tema para a elaboração deste trabalho, surgiu após o ingresso no serviço público em uma Unidade Básica de Saúde com Estratégia da Família, localizada na região metropolitana de Porto Alegre, percebeu-se a necessidade de estabelecer o correto gerenciamento dos resíduos gerados no estabelecimento de saúde. Esta Unidade Básica de Saúde (UBS), localizada no município de Esteio/RS, atende mais de 100 (cem) pessoas por dia, dentre crianças, jovens, adultos, gestantes e idosos.

Os serviços prestados pela unidade são diversificados, promovendo a geração de diferentes tipos de resíduos, potencialmente infectantes (Grupo A), químicos (Grupo B), recicláveis e comuns (Grupo D), e perfurocortantes (Grupo E). Destes resíduos, alguns são segregados e descartados de maneira incorreta, sem a observância das recomendações estabelecidas pela Agência Nacional de Vigilância Sanitária (ANVISA). Além disso, verifica-se que algumas etapas de manejo dos resíduos também estão em desacordo com as normas e legislações. Portanto, este estudo teve como objetivo realizar o diagnóstico dos resíduos gerados na UBS, bem como propor adequações às novas exigências da ANVISA, estabelecidas pela RDC № 222, de 28 de março de 2018 (BRASIL, 2018-B). Essa Resolução regulamenta as boas práticas de gerenciamento dos Resíduos de Serviços de Saúde, sendo obrigatório o seu cumprimento, por parte dos estabelecimentos, a partir do mês de setembro de 2018.

Logo, a adequação à nova Resolução irá impactar positivamente na UBS, visto que melhorias de gerenciamento interno serão realizadas, colaborando, assim, com 
um meio ambiente mais equilibrado e com a saúde dos trabalhadores e pacientes que frequentam este local.

\section{OBJETIVOS}

\section{Objetivo Geral}

Diagnosticar os RSS, gerados na UBS, localizada no município de Esteio/RS, à luz da RDC N²22/2018.

\section{Objetivos Específicos}

- Estudar a Resolução RDC No 222/2018, com o objetivo de verificar as novas exigências da ANVISA, a respeito do gerenciamento dos RSS e elaborar, com base na RDC N²22/2018, o instrumento “Lista de Verificação" (Check List), a ser utilizado para o diagnóstico e acompanhamento periódico dos resíduos gerados na UBS;

- Propor ações de melhoria, necessárias ao correto gerenciamento dos resíduos na UBS, com vistas ao atendimento às exigências da RDC № 222/2018.

\section{ÁREA DE ESTUDO}

A área de estudo do presente trabalho é uma Unidade Básica de Saúde com Estratégia da Família, localizada na região metropolitana de Porto Alegre/RS, que abrange vários municípios, entre eles, o município de Esteio/RS.

Por ser uma (UBS) com Estratégia da Família, tem uma demanda muito maior que os outros postos. Além dos acolhimentos diários, presta toda a assistência necessária às famílias de diferentes microáreas. A Figura 1 apresenta a UBS, logo após sua inauguração, em setembro de 2014.

Figura 1 - Inauguração da UBS em 2014.

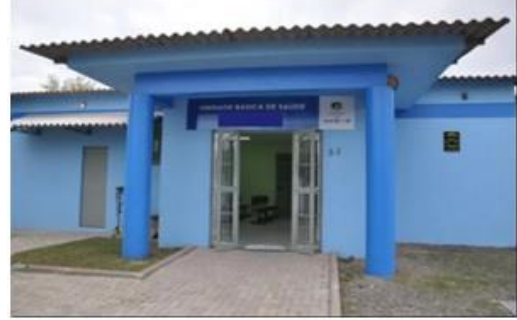

Fonte: http://www.correiodopovo.com.br/Noticias/536133/,UBS-em-Esteio,-passa-a-atender-nasegundafeira 
A UBS é composta por diversos setores, sendo eles administrativos e ambulatoriais, conforme citação a seguir: Recepção, Administração, Sala de Espera, Almoxarifado, Expurgo, Consultório Odontológico, Sala de Vacinação; Depósito de Materiais, Sala de Enfermagem, Sala de Curativos, Consultórios Médicos, Consultório Ginecológico, Sanitários, Copa, Depósito Material de Limpeza e Sala de Reuniões. A disposição dos setores pode ser observada na planta baixa apresentado na Figura 2.

Figura 2 - Planta Baixa, adaptada da Unidade Básica de Saúde.

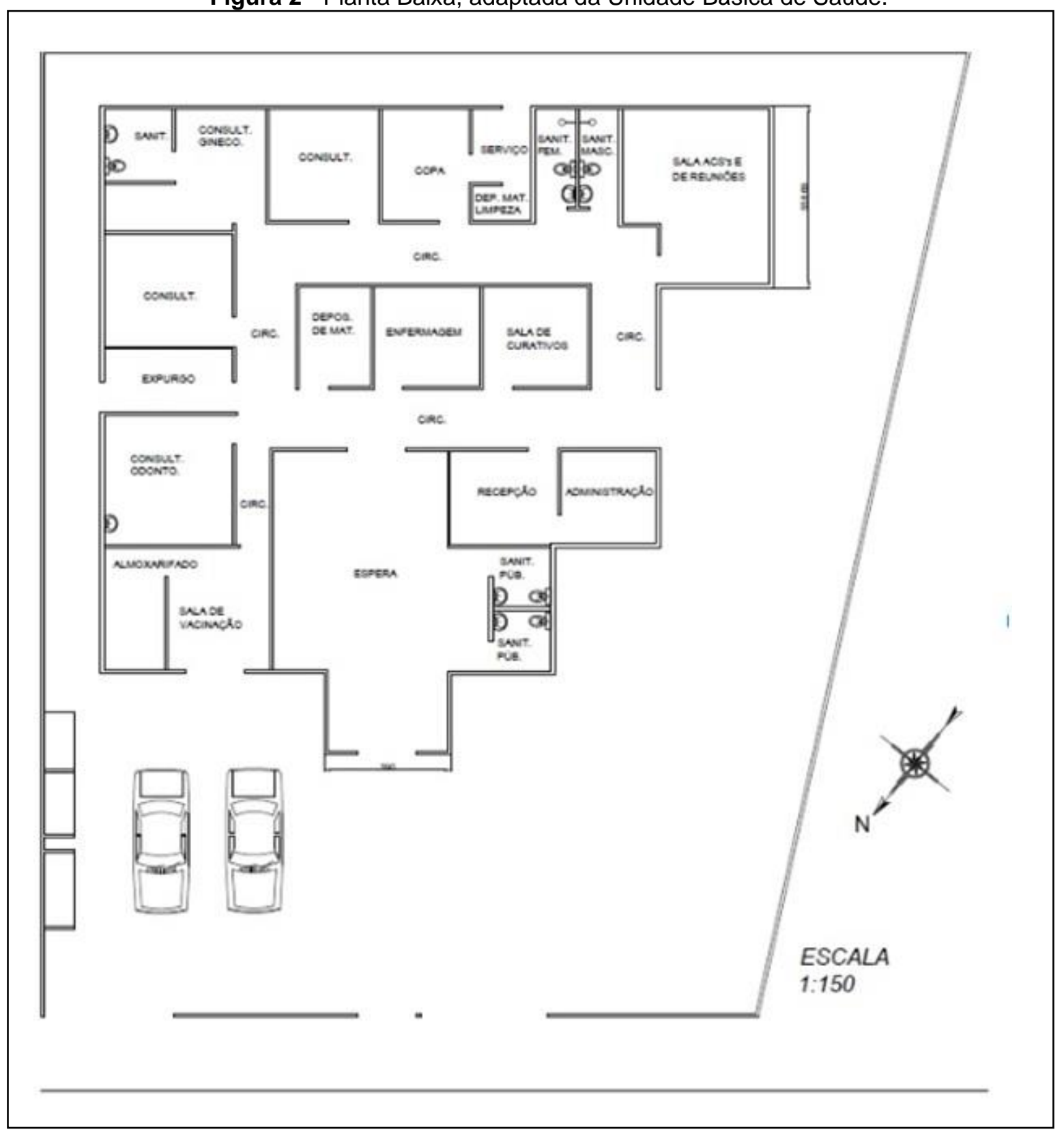

Fonte: Autora, 2019. 
De acordo com o último censo do IBGE (Instituto Brasileiro de Geografia e Estatística) no ano de 2010, o município de Esteio detinha 80.755 habitantes, enquanto a sua população atualmente estimada é de 83.121 habitantes (IBGE, 2018).

\section{MATERIAS E MÉTODOS}

O trabalho desenvolvido contou com as seguintes etapas:

\section{Etapa 1: Estudo da Resolução RDC N²22/2018, com o objetivo de verificar as novas exigências da ANVISA a respeito do gerenciamento dos Resíduos de Serviço de Saúde.}

Esta etapa consistiu na realização de um estudo aprofundado da RDC № 222/2018. Foram estudados todos os artigos, verificando-se as novas exigências da Resolução, destacando-se os pontos mais importantes, tais como: a necessidade de elaboração do documento "Plano de Gerenciamento dos Resíduos do Serviço de Saúde (PGRSS)" e suas exigências para um efetivo gerenciamento; as etapas de manejo, ou seja, as formas como os resíduos devem ser dispostos; os grupos de RSS e seus subgrupos; e a segurança ocupacional das pessoas que realizam o manejo dos RSS.

Etapa 2: Elaboração do instrumento "Lista de Verificação" (Check List), baseado na RDC $\mathbf{N}^{\circ} 222 / 2018$, a ser utilizada para o diagnóstico dos RSS

\section{Gerados na UBS.}

Na etapa 2, após o estudo da RDC N²22/2018, foi elaborado o documento "Lista de Verificação" (Check List), o qual contemplou todos os artigos da referida Resolução e foi utilizado para registro das observações, durante o diagnóstico realizado nos diferentes setores da UBS. No documento "Lista de Verificação" foram contemplados os seguintes aspectos: Descrição, contendo os capítulos da Resolução, desde o Capítulo I que trata sobre as Disposições Iniciais, até o Capítulo $\mathrm{Vl}$, que trata sobre as Disposições Finais e Transitórias da Resolução. Condições de atendimento por parte da UBS, o documento contemplou tópicos como "SIM"- a UBS atende plenamente às exigências para as Boas Práticas de Gerenciamento dos RSS estabelecidas pela Resolução RDC N²22/2018; "NÃO" - 
a UBS não atende às exigências estabelecidas pela Resolução RDC № 222/2018 e "PARCIAL" - a UBS atende parcialmente às exigências estabelecidas pela Resolução RDC N²22/2018, necessitando de adequações para a melhoria nos aspectos estabelecidos.

\section{Etapa 3: Aplicação do instrumento "Lista de Verificação" (Check list) nos diferentes setores da UBS.}

Esta etapa foi realizada da seguinte maneira: depois de elaborada a Lista de Verificação (Check List), a mesma foi impressa para ser utilizada como ferramenta para o estudo. Este documento foi aplicado em todos os setores da Unidade, sendo possível registrar, a partir desse momento, o atendimento da Unidade em relação às especificações exigidas na Resolução. Cabe ressaltar que não pôde ser registrado, com base em uma inspeção visual, o que estava imposto como tópicos na Lista. Esse foram registrados, através da ajuda dos profissionais que se dispuseram a respondê-los da melhor maneira.

\section{Etapa 4: Elaboração do diagnóstico dos resíduos do serviço de saúde, gerados na UBS.}

Após a elaboração do instrumento "Lista de Verificação" (Check List), foi realizada triagem para a elaboração do diagnóstico. É importante salientar que a triagem foi executada, em apenas um dia de trabalho. A triagem ocorreu em dois turnos, no final do turno da manhã e no final do turno da tarde do mesmo dia.

No final do turno da manhã, foram coletados os resíduos das salas de odontologia e curativo/ambulatório, os mesmos foram temporariamente dispostos na sala de expurgo, para que no final do dia fosse estimado o volume de RSS gerados. Já no final do turno da tarde, foram coletados os resíduos da sala de enfermagem/ginecológica, recepção/sala de espera, consultórios médicos, sala de reuniões, sanitários e cozinha. Todos os resíduos coletados foram mantidos na sala de expurgo, juntamente com os resíduos coletados no turno da manhã. Os sacos contendo os resíduos foram etiquetados por setores para melhor organização. Após a coleta desses resíduos em todos os setores, foi feito um cálculo (somatório) baseado no volume do saco de acondicionamento desses resíduos. Salienta-se, ainda, que esse cálculo é uma estimativa dos diferentes grupos de resíduos gerados nos setores da UBS e não um valor exato dos mesmos, já que não foi realizada a verificação da massa de resíduos. O volume de resíduo estimado (por 
grupo) em um dia de trabalho, foi extrapolado para um período de uma semana de atendimento na UBS.

Etapa 5: Proposição de ações de melhoria, necessárias ao correto gerenciamento dos resíduos da UBS, com vistas ao atendimento às exigências estabelecidas pela Resolução RDC № 222/2018.

Após a realização do diagnóstico (estimativa do volume de resíduos gerados na UBS, por grupo) e aplicação do instrumento "Lista de Verificação" (Check List) verificaram-se as áreas que necessitavam de adequações para o completo atendimento da RDC $N^{\circ}$ 222/2018. Nesse sentido, foram propostas ações de melhoria para o correto gerenciamento dos RSS, abrangendo desde recursos materiais, como os objetos e instalações da UBS, até a capacitação dos recursos humanos, como cursos de aperfeiçoamento e sensibilização para o manejo correto dos RSS.

\section{RESULTADOS E DISCUSSÕES}

\section{Elaboração da Lista de Verificação (Check-list)}

Após o estudo da Resolução da Diretoria Colegiada - RDC nº 222/2018, foi elaborado a Lista de verificação (Check list), com o objetivo de auxiliar tecnicamente no diagnóstico da situação de cumprimento da UBS às exigências da referida Resolução. A avaliação, a partir do uso do instrumento "Lista de Verificação" (Check List), contemplou as seguintes três categorias: "SIM" UBS atende plenamente às exigências para as Boas Práticas de Gerenciamento dos RSS estabelecidas pela Resolução RDC N²22/2018; "NÃO" UBS não atende às exigências estabelecidas pela Resolução RDC N²22/2018 e "PARCIAL" UBS atende parcialmente às exigências estabelecidas pela Resolução RDC N²22/2018, necessitando de adequações para a melhoria nos aspectos estabelecidos.

\section{Elaboração do diagnóstico}

Ao acompanhar diariamente os procedimentos realizados em pacientes nos diferentes setores da UBS, percebeu-se que o volume de resíduos do serviço de saúde, gerados neste local é significativo. Assim, surge a necessidade de se elaborar um diagnóstico referente a esses resíduos. Para elaboração do 
diagnóstico, fez-se primeiramente um levantamento do volume de resíduo gerado na UBS.

Na Tabela 1 e nas Figuras 3,4,5 são apresentados os resultados sobre volume de resíduos gerados nos diversos setores da UBS. O volume produzido refere-se a 1 (um) dia de atendimento, o mesmo foi extrapolado para o período de uma semana.

A partir da análise da Tabela 1, verifica-se que o maior volume de resíduo gerado semanalmente é o de resíduo contaminado, classificado como do Grupo A (resíduo infectante) pela RDC № 222/2018, e equivalente a 685 litros de resíduos infectantes, cujo maior gerador é o setor "Sala de Enfermagem". Os resíduos do Grupos B (resíduo químico) não estão quantificados, devido à não adoção pela UBS da prática de segregação e encaminhamento destes para tratamento, sendo os mesmos lançados diretamente na rede de esgotos do município de Esteio/RS. O volume total de resíduos do Grupo D (resíduos recicláveis e comuns) foi de 636 litros, oriundos majoritariamente da recepção e da sala de espera. $\mathrm{O}$ volume de resíduos do Grupo $\mathrm{E}$ (resíduos perfurocortantes) foi de 29 litros, sendo os setores de sala de curativo/ ambulatório e sala de vacinação os setores que mais contribuíram, com 13 litros, cada um, seguido do consultório odontológico, com 3 litros. Cabe ressaltar que na UBS não são gerados resíduos radioativos, portanto, esses não aparecem na Tabela 1.

Tabela 1 - Diagnóstico do Volume de Resíduos Gerados nos Setores da UBS.

\begin{tabular}{|c|c|c|c|c|c|c|c|c|c|c|c|}
\hline Onupes \&e Riesiduss & $\begin{array}{l}\text { Volume (L) } \\
\text { Outio e Semiand }\end{array}$ & $\begin{array}{l}\text { Saba de } \\
\text { Curativo/Ambialatero }\end{array}$ & $\begin{array}{l}\text { Consultones } \\
\text { Madices }\end{array}$ & $\begin{array}{l}\text { Sova de } \\
\text { Vacinacido }\end{array}$ & $\begin{array}{l}\text { Sala of } \\
\text { Rernibo }\end{array}$ & $\begin{array}{l}\text { Consitorio } \\
\text { Odaridologco }\end{array}$ & $\begin{array}{l}\text { Recepclosiala } \\
\text { se Elipera }\end{array}$ & Cosinha & Santarios & $\begin{array}{c}\text { Sala de } \\
\text { Entemagem Girecologica }\end{array}$ & Tetal / Onupo \\
\hline \multirow{2}{*}{ A ansectante) } & VD(L) & $\infty$ & 15 & 2 & 0 & 30 & 0 & 0 & 0 & 50 & $V D=137$ \\
\hline & vs (L) & 200 & 75 & 10 & 0 & 150 & 0 & 0 & 0 & 250 & vs $=\cos 5$ \\
\hline \multirow{2}{*}{$B(0 \mathrm{in} \times 0)$} & Vo(L) & 0 & , & 0 & 0 & · & 0 & 0 & 0 & · & $\mathrm{VD}=0$ \\
\hline & vs (L) & 0 & . & 0 & 0 & - & 0 & 0 & 0 & $\cdot$ & vs $=0$ \\
\hline \multirow{2}{*}{ D Reocavel Comum) } & Vo(L) & 10 & 10 & 10 & 2 & 10 & 30 & 15 & 30 & 10 & $V D=127$ \\
\hline & vs (L) & so & so & 50 & 10 & 50 & 150 & 75 & 150 & 50 & $v_{5}=635$ \\
\hline \multirow{2}{*}{$E$ (Perturocsitume). } & $\mathrm{VD}(\mathrm{L})$ & ? & 0 & . & 0 & 0 & 0 & 0 & 0 & 0 & $\mathrm{VD}=0$ \\
\hline & VS(L) & 13 & 0 & 13 & 0 & 3 & 0 & 0 & 0 & . & $v s=20$ \\
\hline Potal of Residuss / Stetcres & VT(L) & 263 & 125 & 73 & 10 & 209 & 150 & 75 & 150 & 300 & $V T=1340$ \\
\hline
\end{tabular}

Legeda: VD :Volume Diário / VS: Volume Semanal / VT :Volume Total / * Não Quantificado / 0: Não Gerado

Fonte: Autora, 2019.

Considerando a Figura 3, verifica-se que o maior percentual de resíduos é do Grupo A (infectante), o que representa um percentual de $50,7 \%$ de todos os resíduos gerados no período da amostragem na UBS; seguido dos resíduos do Grupo D (reciclável/comum) com percentual de $47,0 \%$ e do Grupo E (perfurocortantes) com 2,3\% do total gerado. Os resíduos do Grupo B (químicos), 
como mencionado anteriormente, não são quantificados na UBS. Conforme verificado por Silva e Rodrigues (2017), em várias unidades públicas de saúde, os resíduos químicos são simplesmente descartados na rede pública de esgoto. A falta de uma gestão ambientalmente adequada dos RSS gerados nas Unidades de Saúde, por vezes, está diretamente relacionada à ausência de um Plano de Gestão de Resíduos de treinamento dos funcionários, conforme preconiza a RDC $\mathrm{N}^{\circ}$ 222/2018 em seus Artigos $5^{\circ}$ e $6^{\circ}$ (BRASIL, 2018-B).

Figura 3 - Percentual volumétrico dos resíduos gerados semanalmente na UBS.

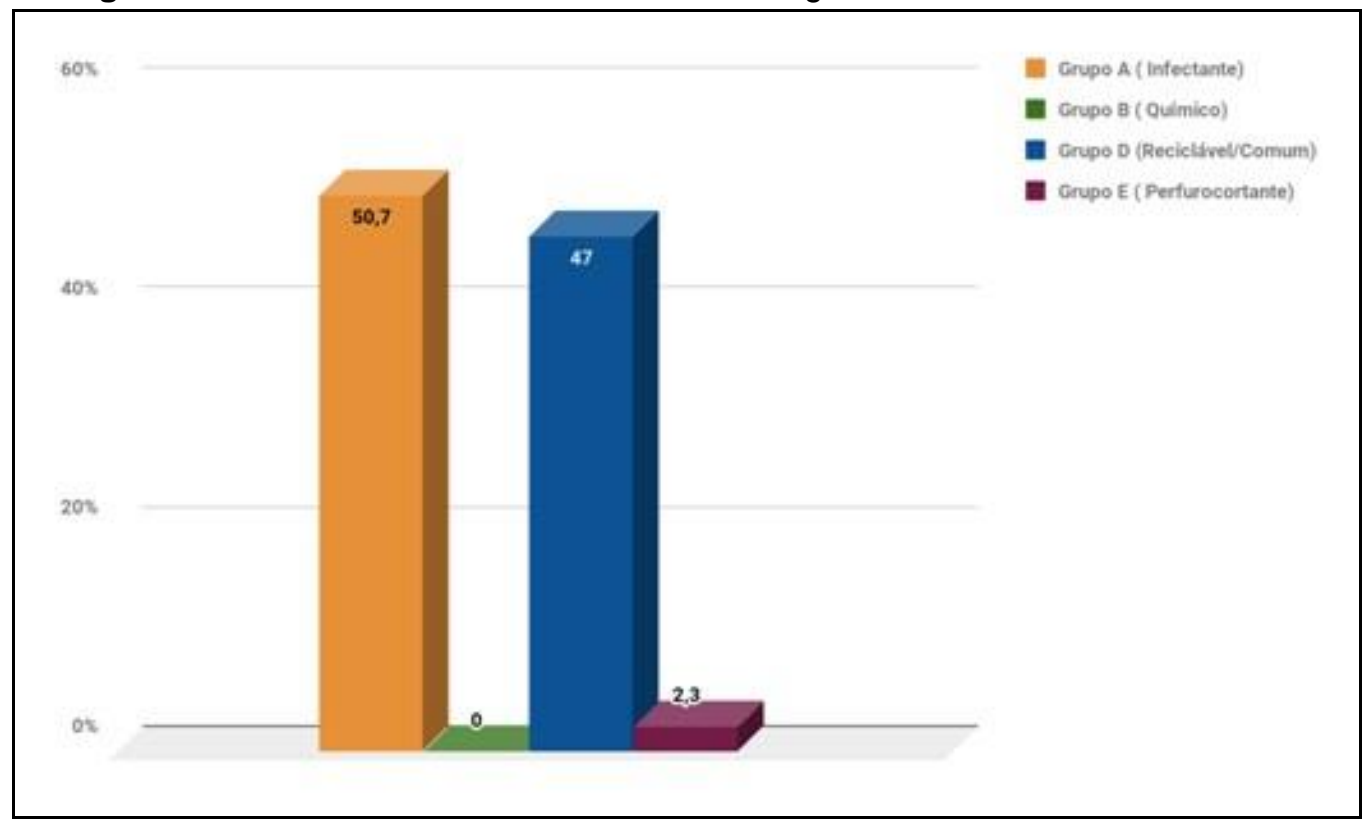

Fonte: Autora, 2019.

Ao analisar a Figura 4, referente ao percentual de resíduos gerados nos setores que compõem a UBS, verificou-se que a sala de enfermagem é a que tem maior contribuição na geração de resíduos, com $22,23 \%$ de todo o resíduo gerado, seguido do setor sala de curativo/ambulatorial com 19,5\%, consultório odontológico com 15,05\%, recepção/sala de espera e sanitários com um mesmo percentual de $11,12 \%$, consultórios médicos com $9,27 \%$, cozinha com $5,56 \%$, sala de vacinação com $5,41 \%$ e sala de reunião com $0,74 \%$. O maior percentual de volume gerado na sala de enfermagem é justificado pelo fato de ser o setor que realiza grande parte dos procedimentos da UBS. Por conseguinte, o menor percentual de resíduos gerados na sala de reunião se explica pelo fato da mesma ser pouco utilizada, pois a maioria das reuniões são realizadas na sala de espera, onde cabe um maior número de pessoas. 
Figura 4 - Percentual volumétrico dos resíduos gerados nos setores da UBS.

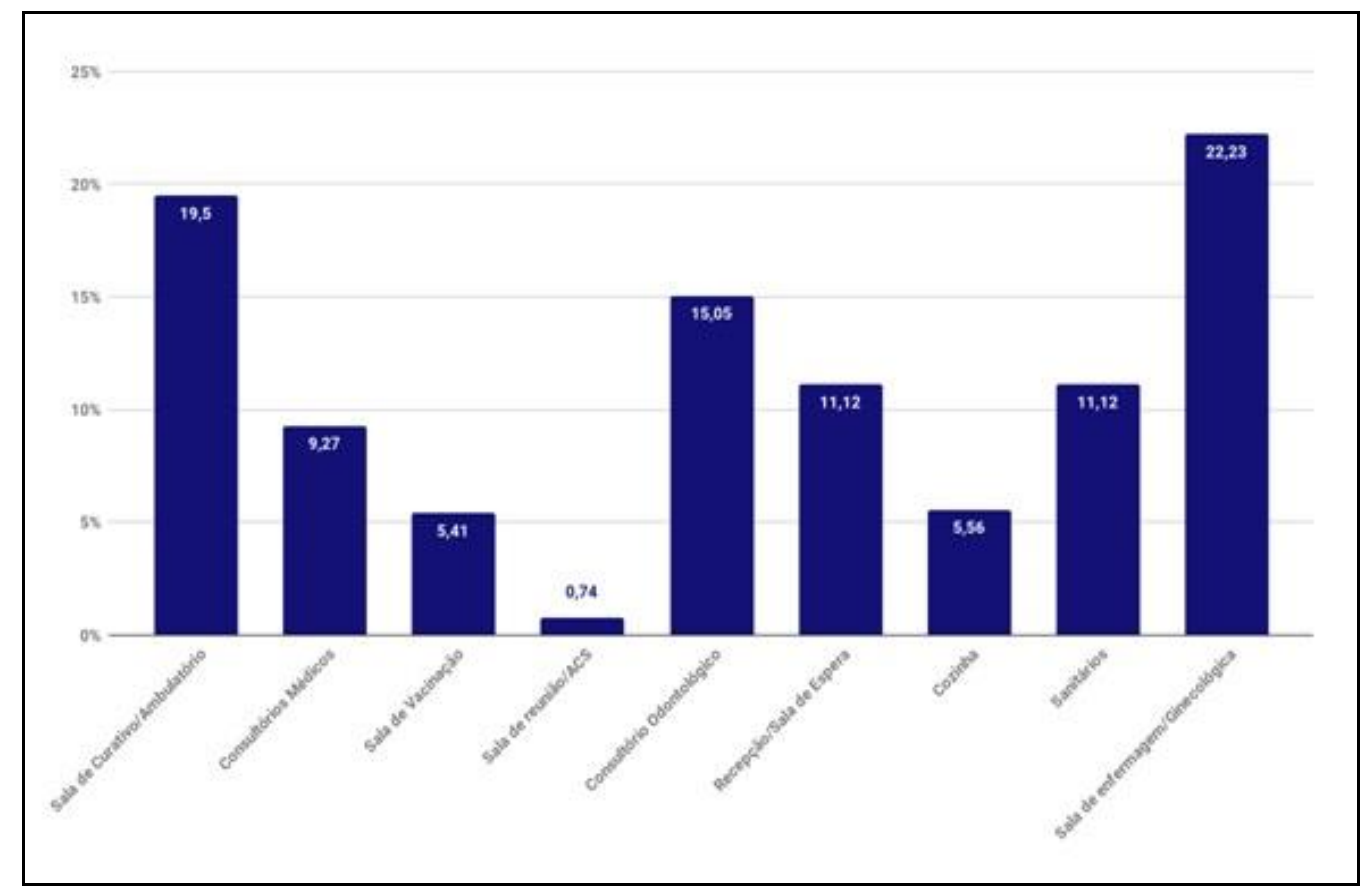

Fonte: Autora, 2019.

Ainda sobre o volume de resíduos gerados na UBS, observa-se na Figura 5, o detalhamento do percentual total gerados por grupos em cada setor. Verifica-se que na maioria dos setores, o resíduo que possui um percentual maior de geração, é o resíduo infectante pertencente ao Grupo A, seguido do resíduo reciclável pertencente ao Grupo D. A sala de enfermagem, é o local que gera maior volume de resíduo infectante, com uma porcentagem de 83,3\%. Na maioria das vezes estes resíduos não são segregados corretamente, os mesmos são misturados com outros grupos de resíduos, como por exemplo, os recicláveis. De acordo com Viana (2001) apud Alves (2010), "a equipe de enfermagem é a principal responsável pelos procedimentos realizados nos pacientes, fazendo com que a categoria seja uma das principais geradoras de resíduos nas instituições". Por ser um dos principais geradores de resíduos na UBS, a equipe de enfermagem deve ser sensibilizada quanto à necessidade de descarte dos resíduos nos seus devidos recipientes. Assim, pode-se afirmar que um PGRSS eficiente é fundamental para estabelecer normativas, visando uma gestão adequada dos resíduos de serviços de saúde e a segurança dos profissionais que manuseiam diretamente ou indiretamente estes resíduos. 
Figura 5 - Percentual por grupos de resíduos gerados nos setores da UBS.

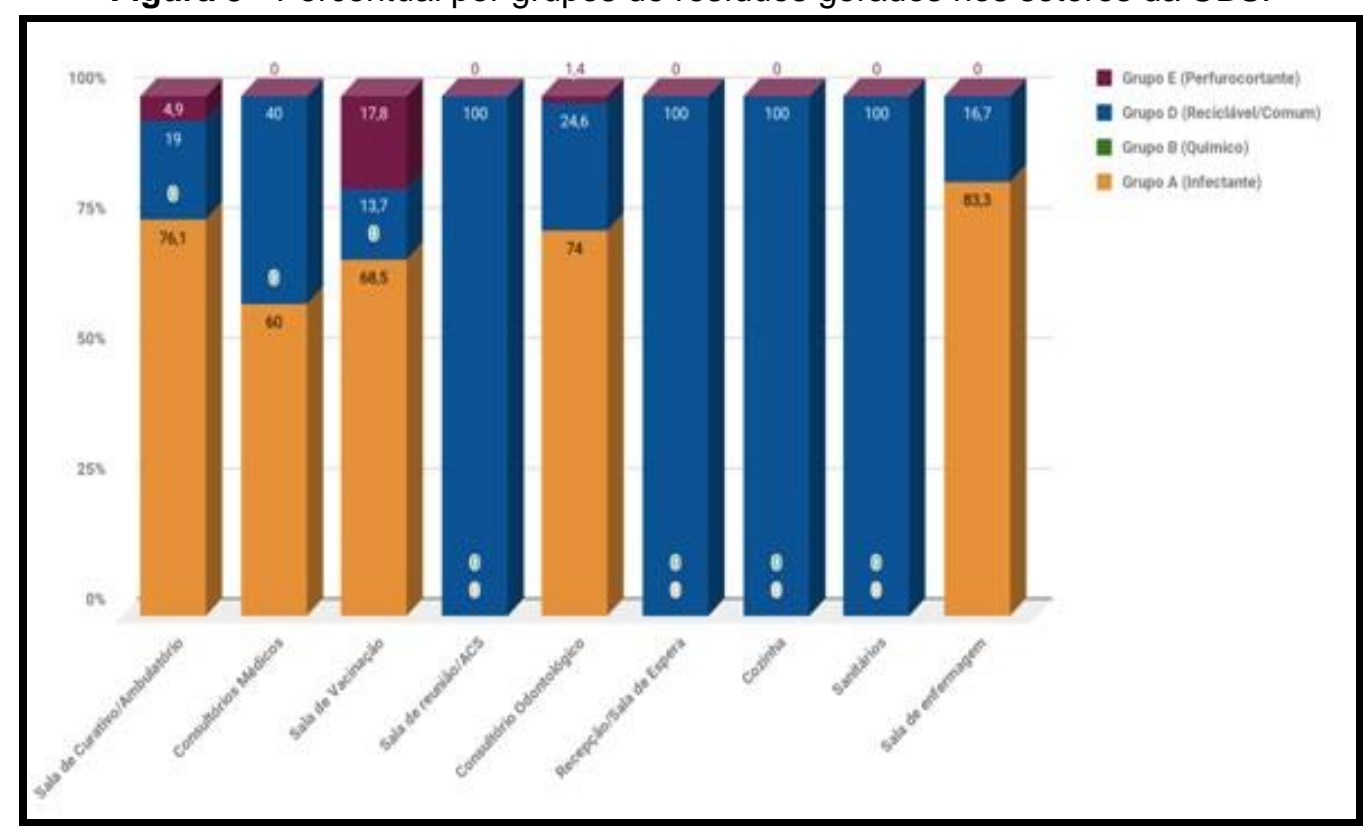

Fonte: Autora, 2019.

Após a avaliação do volume de resíduos gerados, partiu-se para a análise da gestão desses resíduos gerados na UBS. A RDC № 222/2018 (BRASIL, 2018-B), ao retratar as boas práticas de gerenciamento de resíduos de serviços de saúde, objetiva "minimizar os riscos inerentes ao gerenciamento de resíduos no que diz respeito à saúde humana e animal, assim como a proteção ao meio ambiente e aos recursos naturais renováveis".

Assim, para auxiliar no gerenciamento desses RSS, foi elaborado o documento, que descreve todas as ações relativas à gestão dos resíduos nas fontes geradoras. Este documento, contempla toda a parte de manejo dos resíduos desde as etapas de geração e segregação, acondicionamento, identificação, armazenamento, coleta, transporte, tratamento e destinação ambientalmente adequada (BRASIL, 2018-B).

A seguir será apresentado o diagnóstico que foi realizado na UBS, e descrito nas seguintes etapas: geração e segregação; acondicionamento; identificação; armazenamento interno, temporário e externo; coleta externa, tratamento e disposição final; gerenciamento dos grupos de RSS; segurança ocupacional; análise dos registros da lista de verificação (Check List) e proposição de ações de melhoria.

a) Geração e Segregação: 
Diariamente, é gerada uma quantidade significativa de resíduos na UBS, devido ao intenso fluxo de pacientes em busca de atendimento. Constatou-se que estes nem sempre são segregados corretamente, sendo um dos desafios de adequação no gerenciamento de RSS a ser enfrentado pela UBS.

Conforme o Art. $11^{\circ}$ da Resolução comentada RDC № 222/2018, os RSS devem ser segregados no momento de sua geração, de acordo com a classificação por grupos, em função do risco presente. Um eficiente gerenciamento de resíduos de serviços de saúde deve ter como regra a segregação na fonte, resultando na diminuição do volume de resíduos com potencial de risco e ocorrência de acidentes ocupacionais.

Ainda tratando da segregação, é de suma importância citar algumas das vantagens de praticar a separação correta dos resíduos na fonte, como: diminuição dos riscos para a saúde e o ambiente, redução de gastos com o tratamento dos mesmos, já que apenas uma parte precisará de tratamento especial, e aumento da eficácia da reciclagem (BRASIL, 2018-C).

A partir do diagnóstico realizado, podem-se verificar alguns dos resíduos gerados na "Sala de Enfermagem" (Figura-6). Os resíduos estão corretamente acondicionados em um saco branco leitoso, destinado para os resíduos infectantes do Grupo A. No entanto, os mesmos encontram-se misturados, verificando-se a presença de resíduos contaminados, como luvas, que possuem fluidos corporais, acondicionadas juntamente com resíduos recicláveis e comuns, como a caixa de luvas e papel toalha, respectivamente.

Figura 6 - Acondicionamento dos resíduos na sala de enfermagem.

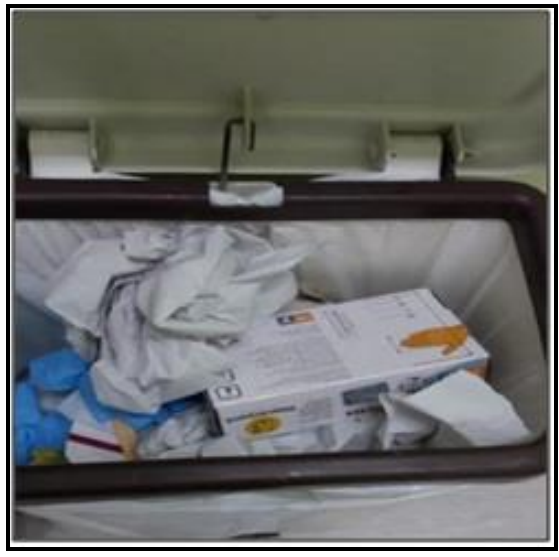

Fonte: Autora, 2019. 
Destacam-se, também, os resíduos gerados na "Sala de Odontologia" e sua segregação. A partir da análise das Figuras 07-A, 07-B e 07-C, percebe-se uma divergência na segregação dos resíduos. Na Figura 07-A é possível verificar resíduos recicláveis acondicionados no saco branco leitoso, que é utilizado para resíduos infectantes. Na Figura 07-B verificam-se embalagens de materiais recicláveis depositadas no coletor identificado como "Lixo Perigoso", cujo saco plástico utilizado para revestir o coletor, foi o saco branco leitoso, o qual deve ser utilizado para resíduos do Grupo A (infectantes). Ainda referente às Figuras 07-A e 07-B, como os coletores foram revestidos com saco branco leitoso, provavelmente no fundo desses, há luvas, algodões e máscaras com fluídos corporais. A falta da correta segregação dos resíduos na fonte geradora, proporciona a mistura dos mesmos e, consequentemente, a sua contaminação. Na Figura 07-C, observa-se que o saco que acondiciona os resíduos, é de cor preta, para resíduos recicláveis, verifica-se, portanto, que não há deficiência de acesso aos coletores adequados. Acredita-se que a segregação incorreta dos resíduos ocorra devido à ausência do Plano de Gerenciamento dos Resíduos, descrição de procedimentos para descarte de resíduos e treinamento dos profissionais, conforme preconiza a RDC $\mathrm{N}^{\circ}$ 222/2018 em seus Artigos $5^{\circ}$ e $6^{\circ}$ (BRASIL, 2018-B).

Figuras 07-A, 07-B e 07-C - Resíduos gerados e segregados na sala de odontologia.
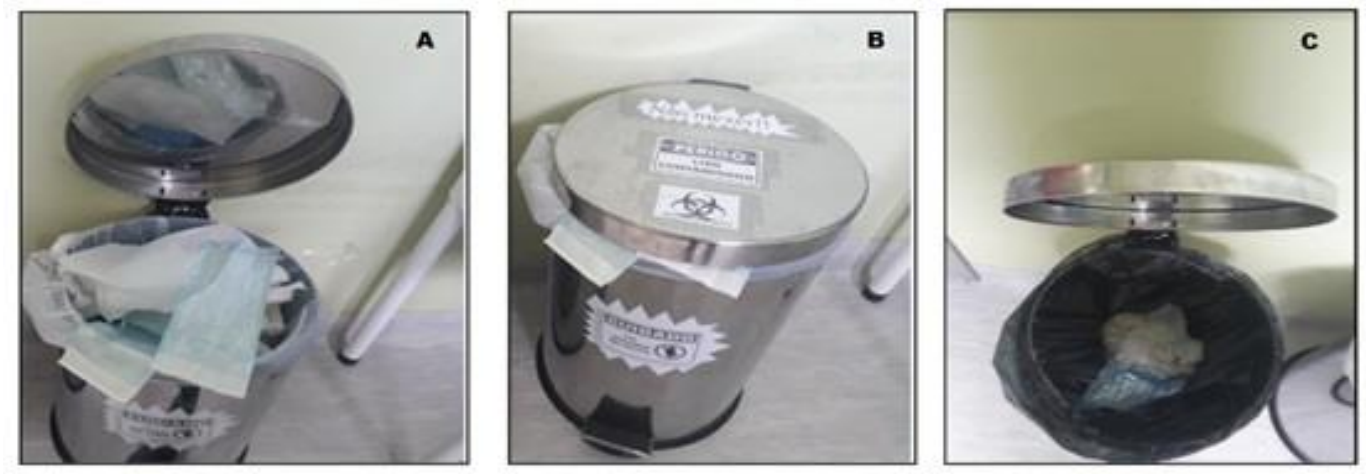

Fonte: Autora, 2019

A análise dos resíduos gerados no setor "Sala de Curativos" será apresentada a seguir. Observa-se, também, que na "Sala de Curativos", os resíduos não são segregados corretamente, encontrando-se misturados. Nas Figuras 08-A e 08-B é possível verificar uma embalagem plástica, provavelmente, a da própria atadura misturada a papéis toalhas e ataduras com gaze, utilizadas durante o procedimento de realização dos curativos. Na Figura $08-C$, verificam-se resíduos comuns, como 
papéis toalhas, acondicionados com os resíduos contaminados, como algodões e luvas utilizadas nos procedimentos, com provável contaminação por fluidos biológicos. Além disso, na Figura 08-C verifica-se um equipo com frasco de soro, descartado no mesmo recipiente de resíduos contaminados. A segregação correta deveria priorizar o seguinte procedimento, qual seja: ponteira do equipo com ou sem sangue, descartada no coletor de resíduos perfurocortantes; mangueira destinada ao coletor de resíduos contaminados, caso haja a presença de algum fluído e o frasco do soro no reciclável, destinado aos resíduos recicláveis.

Figuras 08-A, 08-B e 08-C - Segregação dos resíduos na sala de curativos.
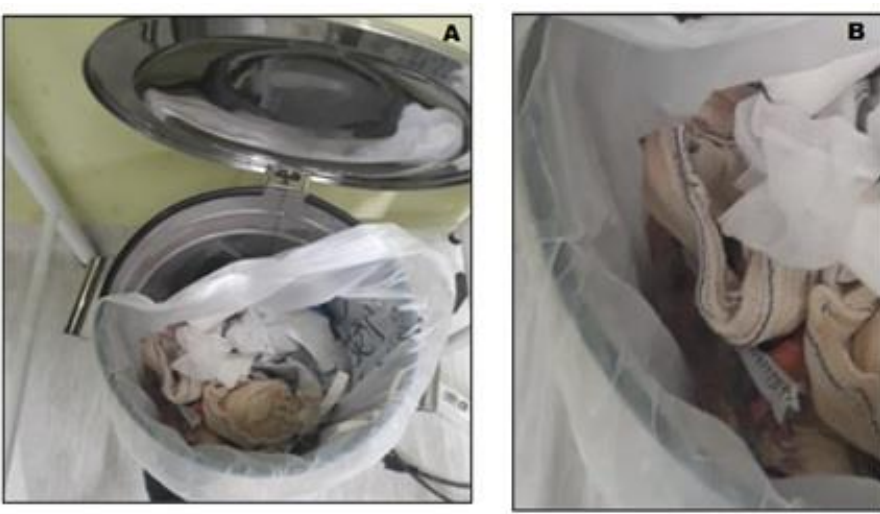

Fonte: Autora, 2019.

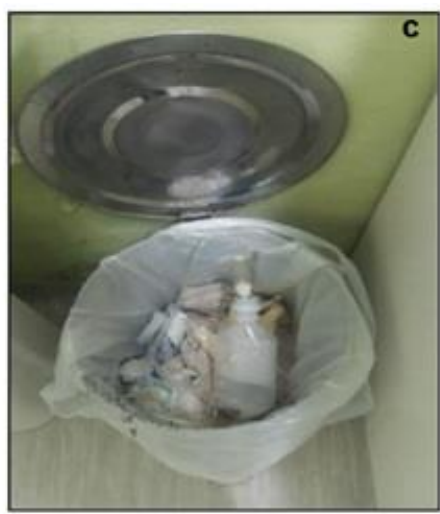

Os resíduos gerados e segregados nos "Consultórios Médicos" da Unidade serão apresentados, posteriormente. Ao explorar os consultórios médicos e analisar os coletores, constatou-se que os resíduos também se encontravam misturados. Nas Figuras 09-A e 09-B, observa-se que os sacos presentes nos coletores para o acondicionamento dos resíduos são do tipo saco branco leitoso, destinados para os resíduos infectantes pertencentes ao Grupo A, conforme estabelecido no anexo II da Resolução № 222/2018, que trata sobre a identificação dos grupos de resíduos de serviços de saúde (BRASIL, 2018-B). Entretanto, verifica-se nestes coletores, resíduos comuns e recicláveis pertencentes ao Grupo D, como fralda, papéis toalhas e embalagem vazia, respectivamente, junto com luvas, abaixador de língua e outros resíduos possivelmente contaminados. 
Figuras 09-A e 09-B - Coletores para resíduos do grupo A.
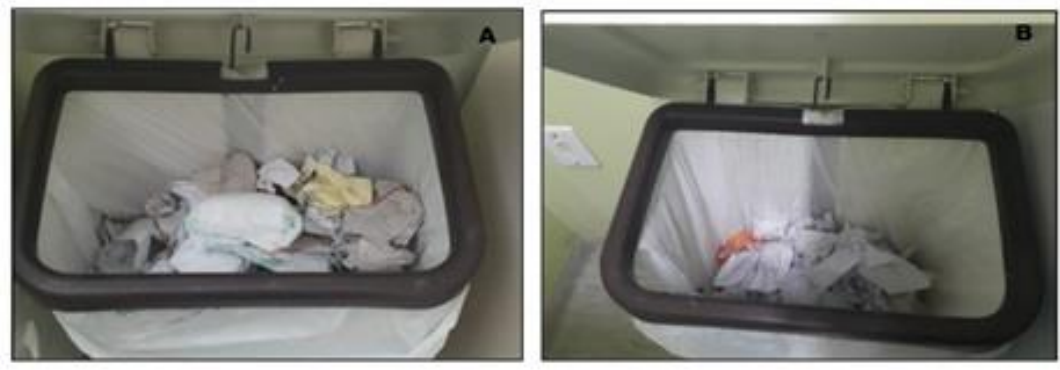

Fonte: Autora, 2019.

Ainda referente aos "Consultórios Médicos" é importante salientar que os coletores de resíduos infectantes ficam expostos em um lugar do consultório onde os pacientes também têm acesso, justificando-se, assim, o motivo de ter uma fralda descartada incorretamente nos resíduos infectantes. Todos os consultórios possuem, além do coletor para resíduos infectantes, um coletor para resíduos recicláveis/comuns. No entanto, esses coletores, teoricamente de resíduos comuns, não estão de acordo com as exigências estabelecidas pela legislação, ou seja, estão em locais não acessíveis aos pacientes, por exemplo, embaixo da mesa dos médicos.

Outro aspecto abordado na RDC comentada № 222/2018, Art. 17ํe é que o coletor dentre outras exigências, deve possuir tampa, provida de sistema de abertura sem contato manual (BRASIL, 2018-C). Todavia, verificam-se nas Figuras 10-A e 10-B que os coletores não possuem tampas, ainda na Figura 10-A percebese que o coletor está totalmente inadequado para acondicionar os resíduos recicláveis/comuns pertencentes ao Grupo D, sendo rotulado como Grupo - " Substância Química", revestido com um saco branco leitoso para resíduo infectante - Grupo A e, ainda, armazenando resíduo reciclável, como o jornal.

Figuras 10-A e 10-B - Resíduos misturados e em coletores inadequados.
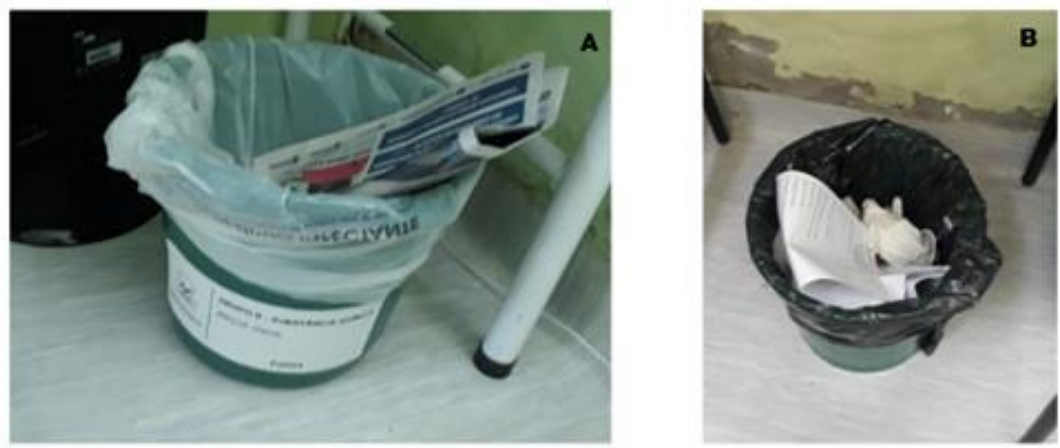

Fonte: Autora, 2019.

O diagnóstico dos resíduos gerados e segregados na "Cozinha" da UBS será apresentado a seguir. $\mathrm{Na}$ cozinha também, assim como nos outros setores, os 
resíduos não são segregados corretamente. Observam-se nas Figuras 11-A e 11-B que os resíduos comuns estão misturados com os resíduos recicláveis, e que na cozinha possui apenas um coletor, identificado como "Resíduo Reciclável". Contudo, tanto restos de comida, papéis molhados, quanto embalagens vazias e sacolas plásticas são descartados neste único coletor.

Figuras 11-A e 11-B - Coletores de resíduos recicláveis e orgânicos.
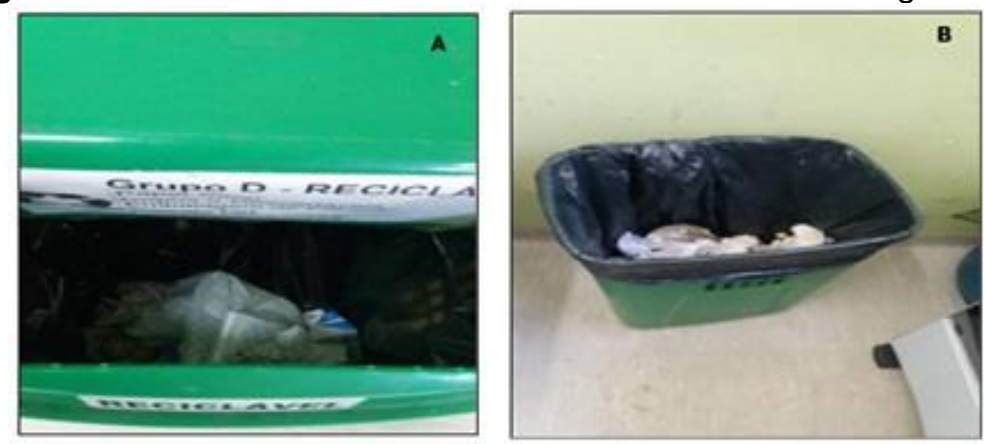

Fonte: Autora, 2019.

b) Acondicionamento:

O acondicionamento é o ato de embalar os resíduos segregados, em sacos ou recipientes. De acordo com a RDC comentada N N 222/2018, "um acondicionamento incorreto compromete a segurança do processo e o encarece". Conforme o Art. $13^{\circ}$ da mesma Resolução, os "RSS no estado sólido, quando não houver orientação específica, devem ser acondicionados em saco constituído de material resistente a ruptura, vazamento e impermeável”. (BRASIL, 2018-C). O parágrafo $2^{\circ}$, deste mesmo artigo cita também a proibição do esvaziamento ou reaproveitamento dos sacos de acondicionamento de resíduos (BRASIL, 2018-C).

Por conseguinte, com a elaboração do diagnóstico, foi possível observar que a prática não está condizente com a teoria. Na UBS os resíduos recicláveis e comuns classificados como Grupo D, que estão armazenados em sacos com menor volume, geralmente 30 litros, ao serem coletados nos setores, são transferidos para um único saco de cor preta de maior volume, normalmente 130 litros, conforme apresentado na Figura 12. Sendo assim, verificou-se que os sacos menores, contendo esses resíduos, são esvaziados e reaproveitados. 
Figura 12 - Acondicionamento dos resíduos Grupo-D em um único saco.

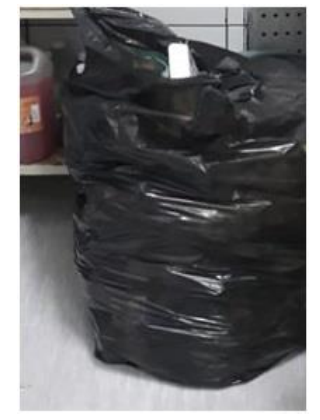

Fonte: Autora, 2019.

Referente ao coletor para acondicionamento dos RSS o Art. $17^{\circ} \mathrm{da}$ Resolução comentada № 222/2018, cita que "o coletor deve ser de material liso, lavável, resistente a punctura, ruptura, vazamento e tombamento, com tampa provida de sistema de abertura sem contato manual, com cantos arredondados" (BRASIL, 2018-C). Ao realizar a pesquisa na UBS, constatou-se que alguns coletores não estão totalmente de acordo com o especificado na Resolução. Como se verifica nas Figuras 13-A e 13-B, para abrir os coletores é necessário o contato manual com a tampa, pois o mesmo não tem sistema de abertura com pedal.

Figuras 13-A e 13-B - Coletor sem sistema de abertura com pedal.
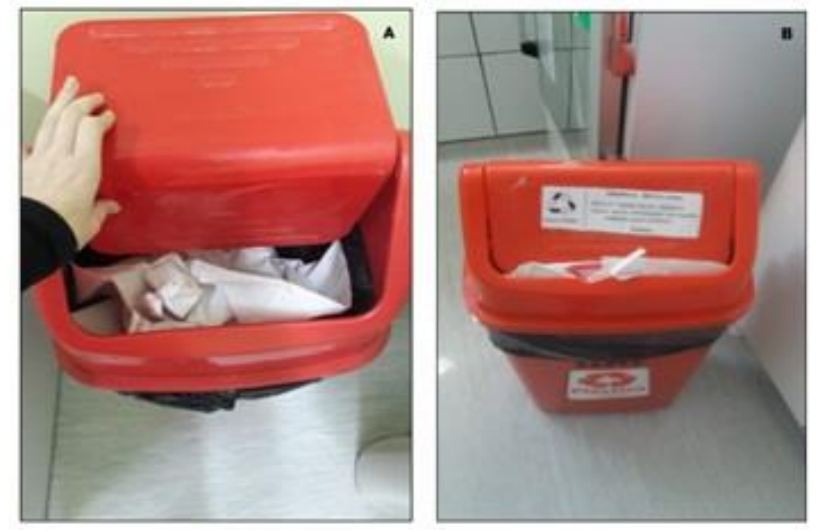

Fonte: Autora, 2019.

Tratando-se, ainda, do Art. $17^{\circ}$ parágrafo $2^{\circ}$, da Resolução comentada № 222/2018, "os sacos após serem substituídos, não podem ser colocados diretamente no chão de abrigos temporários, expurgos, ou outro local que não seja o carro que faz a coleta dos RSS" (BRASIL, 2018-C). Ao realizar o estudo para a elaboração deste trabalho, verificou-se que na UBS os sacos para acondicionamento dos resíduos, ao serem substituídos e recolhidos dos setores no final da manhã, horário que geralmente são higienizadas as salas, são colocados provisoriamente no chão da sala de expurgo, como pode ser observado nas Figuras 
14-A e 14-B. Estes sacos permanecem no expurgo até o final da tarde, horário que são recolhidos novamente mais resíduos de outros setores para serem colocados todos juntos no abrigo externo da Unidade.

Figuras 14-A e 14-B - Sacos acondicionados no chão da sala de expurgo.
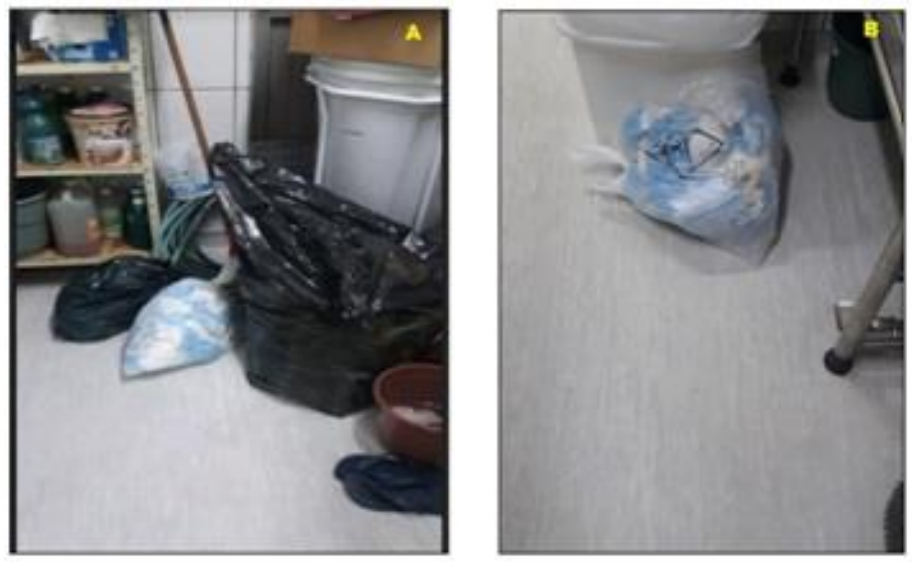

Fonte: Autora, 2019.

Observou-se, ainda, que as caixas "Descarpack", utilizadas para acondicionar os resíduos perfurocortantes, do mesmo modo que os outros grupos de resíduos, estão em contato direto no chão do expurgo, permanecendo no local por até uma semana, até que sejam recolhidos pela empresa terceirizada. Nas Figuras 15-A e 15-B é possível verificar as caixas com resíduos perfurocortantes no chão do expurgo e também no corredor da UBS, outro local que não é permitido.

Figuras 15-A e 15-B - Resíduos perfurocortantes acondicionadas no chão e corredor da UBS.
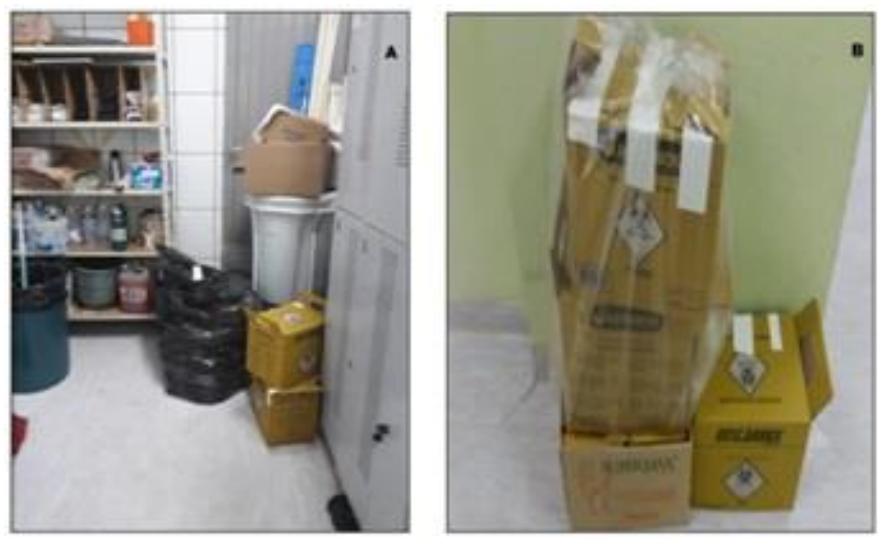

Fonte: Autora, 2019

Percebeu-se, também, que nos setores "Sala de Odontologia e na Sala de Vacinação", as caixas de materiais perfurocortantes não estão acondicionadas em um local adequado. Verifica-se na Figura 16-A que na "Sala de Odontologia", a caixa com perfurocortantes está colocada no chão, facilitando, assim, possíveis 
acidentes. Já na Figura 16-B, observa-se que na "Sala de Vacinação" a caixa com os materiais perfurocortantes está em cima da pia. Conforme a Resolução comentada RDC N²22/2018, "o que se recomenda é que o recipiente não fique em local inadequado, como em cima de pias, por exemplo, ou outro local que possa molhar, rasgar ou outra situação que possa colocar em risco os pacientes e profissionais envolvidos no processo de trabalho" (BRASIL, 2018-C).

Figuras 16-A e 16-B - Caixas com perfurocortantes no chão e na pia.
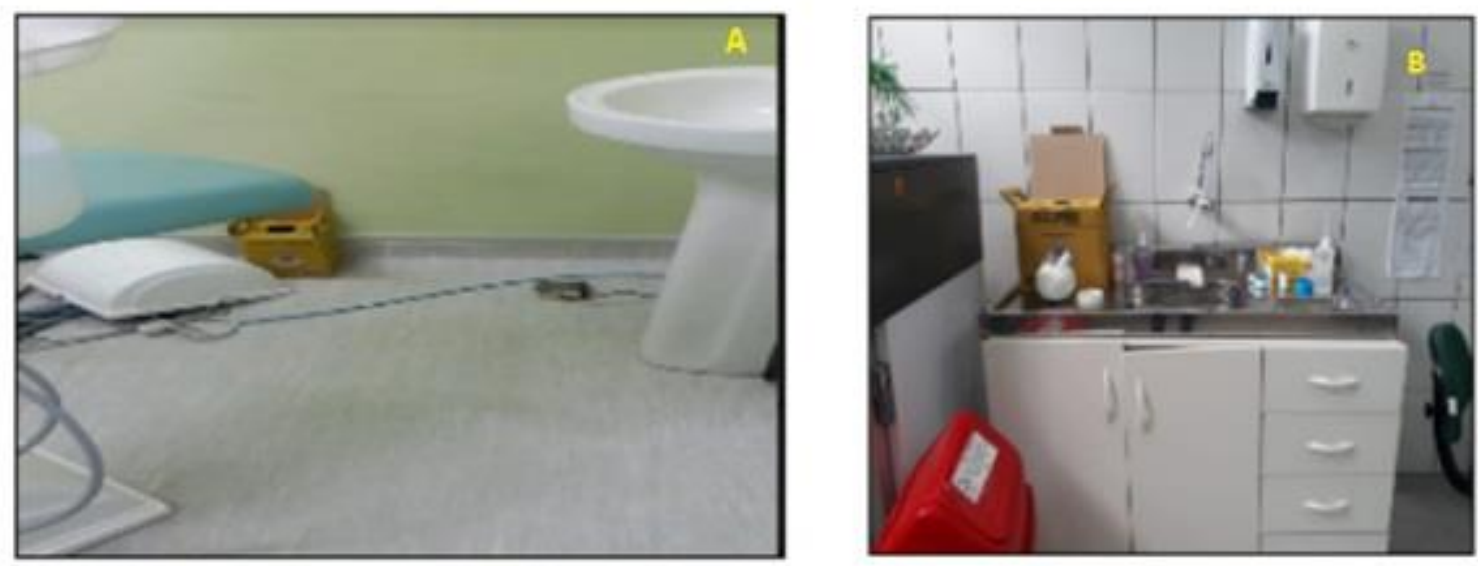

Fonte: Autora, 2019.

O Art. 23 da RDC № 222/2018 cita a forma de acondicionamento dos RSS, gerados pelos serviços de atenção domiciliar, onde estes "devem ser recolhidos pelos próprios agentes de atendimento ou por pessoa treinada para a atividade e encaminhados à destinação final ambientalmente adequada" (BRASIL, 2018-B). Entretanto, a partir do diagnóstico, pode-se verificar que na UBS, os resíduos gerados nas visitas domiciliares não são recolhidos pelo profissional que está prestando o serviço, ficando sob a responsabilidade do paciente ou familiar o descarte "correto" deste resíduo gerado.

c) Identificação:

De acordo com a Resolução RDC N²22/2018, Art. 22, "a identificação dos resíduos de serviços de saúde (RSS) é um conjunto de medidas que permite o reconhecimento dos riscos presentes nos resíduos acondicionados, de forma clara e legível " (BRASIL, 2018-B). Ainda de acordo com o Art. 22, parágrafo $2^{\circ}$, "os sacos que acondicionam os resíduos (exceto os resíduos do grupo D), os coletores e os carros de coleta devem estar identificados" (BRASIL, 2018-B). 
Ao analisar a gestão dos RSS da UBS, constatou-se que não existe um carro de coleta para resíduos, sendo a funcionária responsável pela higienização do local, incumbida de coletar, manualmente, os resíduos internos. Já referente aos coletores de resíduos, foi possível verificar na UBS, que alguns não estão identificados. Observa-se nas Figuras 17-A a 17-D a ausência de identificação dos coletores, armazenados nos diferentes setores da UBS. Sendo esta identificação de suma importância, visto que não são somente os profissionais que têm acesso aos setores, mas também os pacientes. Salienta-se, também, a relevância de se identificar os coletores de resíduos, premissa básica para a correta segregação dos mesmos.

Figuras 17-A a 17-D - Coletores sem identificação na UBS.
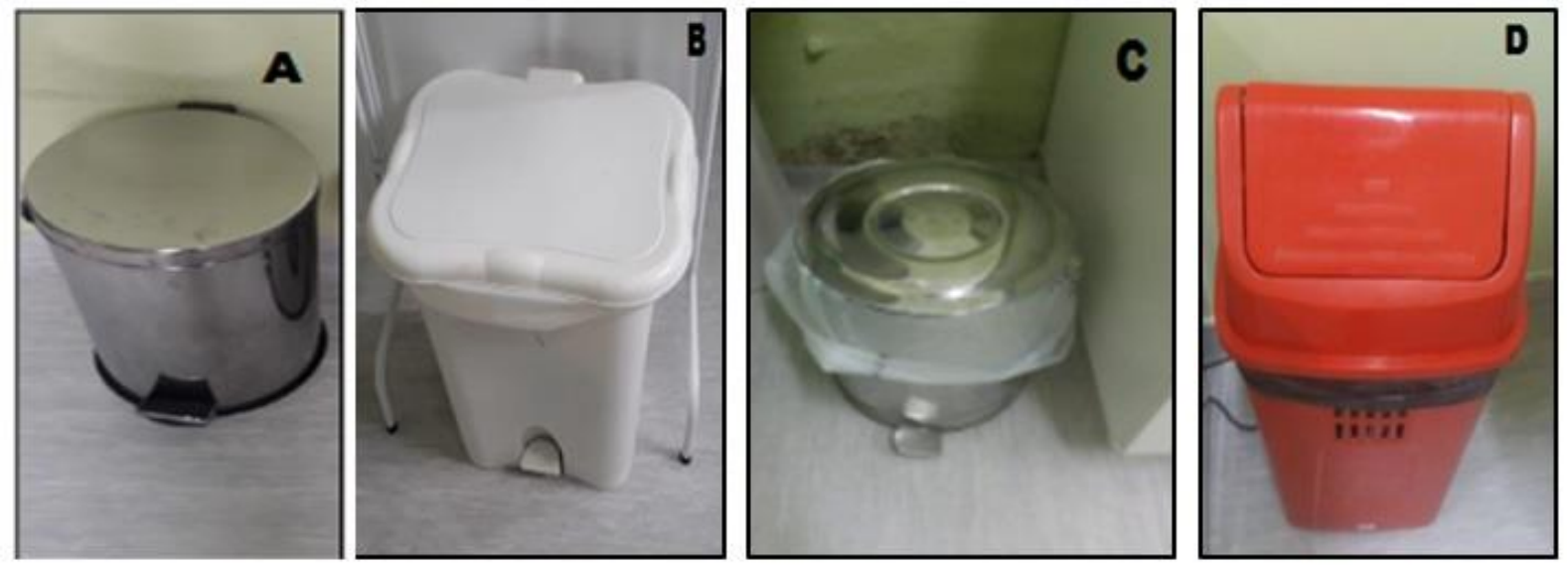

Fonte: Autora 2019.

d) Armazenamento Interno, Temporário e Externo:

Conforme a Resolução RDC №222/2018 "o armazenamento interno é a guarda do resíduo, contendo produto químico ou rejeito radioativo na área de trabalho" (BRASIL, 2018-B). A partir do diagnóstico realizado, foi possível verificar que na UBS não possui armazenamento interno, isso se deve ao fato de não ser gerado resíduo radioativo e os resíduos químicos não serem segregados, ou seja, os mesmos são descartados diretamente na rede de esgoto do município e Esteio/RS (BRASIL, 2018-B).

Segundo a Resolução RDC N²22/2018, "a sala de utilidades ou expurgo", pode ser compartilhada para o armazenamento temporário dos RSS dos Grupos A, E e D, devendo ser compatível com a área a ser ocupada pelos coletores em uso". No entanto, a sala de utilidades ou expurgo deve conter também a identificação com a 
inscrição "Abrigo Temporário de Resíduos" (BRASIL, 2018-B). Na UBS, foi possível verificar que os resíduos são armazenados temporariamente na sala de expurgo. Os resíduos dos grupos A e D, classificados como infectantes e recicláveis, respectivamente são dispostos na sala de expurgo até o término da limpeza da UBS. O mesmo ocorre com os resíduos do grupo E, classificados como perfurocortantes; porém, estes permanecem no expurgo pelo prazo de até uma semana. Por este motivo, o expurgo da UBS, conforme apresentado na Figura 18A, deveria ser identificado, também, como "Abrigo Temporário de Resíduos". Entretanto, como mostrado na Figura 18-B, é possível observar que na porta do expurgo da UBS, não possui tal identificação, estando, assim, em desacordo com as exigências estabelecidas pela Resolução.

Figuras 18-A e 18-B - Sala de expurgo sem a identificação " Abrigo Temporário de Resíduo"
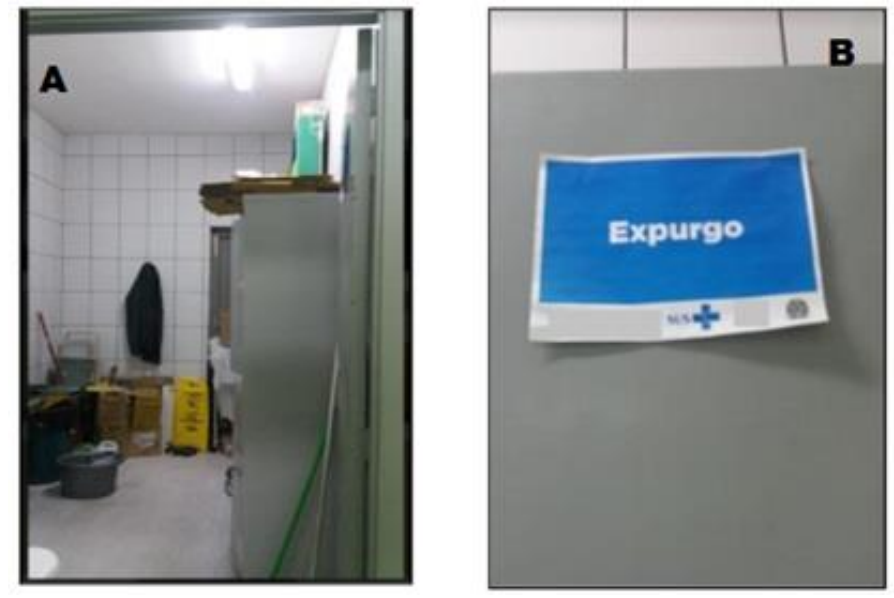

Fonte: Autora, 2019.

A Resolução RDC N²22/2018, cita em seu Art. 35ํㅜ como deve ser um abrigo externo (armazenamento externo) de resíduos do serviço de saúde, e dentre as exigências estão:

I - Permitir fácil acesso às operações do transporte interno; II Permitir fácil acesso aos veículos de coleta externa; III - Ser dimensionado com capacidade de armazenagem mínima equivalente à ausência de uma coleta regular, obedecendo à frequência de coleta de cada grupo de RSS; IV - Ser construído com piso, paredes e teto de material resistente, lavável e de fácil higienização, com aberturas para ventilação e com tela de proteção contra acesso de vetores; V - Ser identificado conforme os Grupos de RSS armazenados; VI - Ser de acesso restrito às pessoas envolvidas no manejo de RSS; VII - Possuir porta com abertura para fora, provida de proteção inferior contra roedores e vetores, com dimensões compatíveis com as dos coletores utilizados; VIII - Ter ponto de iluminação; IX - Possuir canaletas para o escoamento dos 
efluentes de lavagem, direcionadas para a rede de esgoto, com ralo sifonado com tampa; $\mathbf{X}$ - Possuir área coberta para pesagem dos RSS, quando couber; XI - Possuir área coberta, com ponto de saída de água, para higienização e limpeza dos coletores utilizados (BRASIL, 2018-B).

Ao analisar a estrutura externa que abriga os resíduos na UBS, verificou-se que o mesmo necessita de melhorias. Segundo o Art. 27 da Resolução RDC No 222/2018, "no abrigo externo de RSS, é obrigatório manter os sacos acondicionados dentro de coletores com a tampa fechada" (BRASIL, 2018-B). No entanto, conforme apresentado na Figura 19-A, é possível observar que os sacos que acondicionam os resíduos ficam dentro do coletor sem a tampa, pois a mesma se encontra no chão, ou ainda, conforme verificado na Figura 19-B, uma parte dos sacos ficam dentro do coletor e outra no chão do abrigo.

Figuras 19-A e 19-B - Sacos acondicionados de forma errada no abrigo externo.

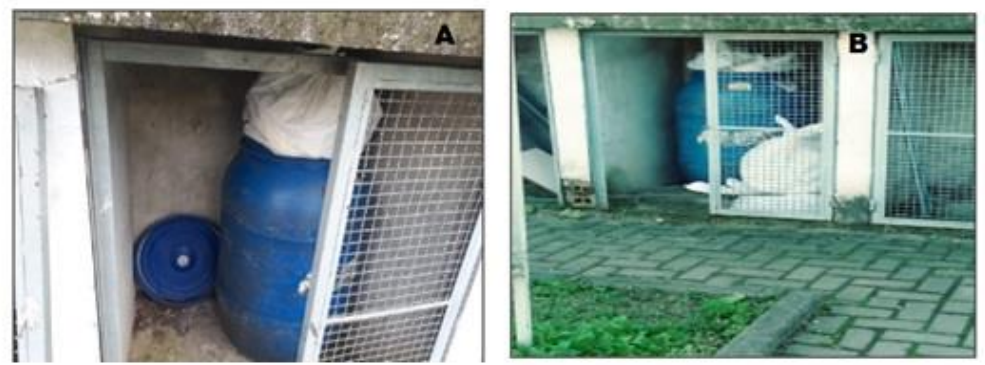

Fonte: Autora, 2019.

A Resolução RDC No 222/2018, exige, também, que "o abrigo seja construído com piso, paredes e teto de material resistente, lavável e de fácil higienização, com aberturas para ventilação e com tela de proteção contra acesso de vetores" (BRASIL, 2018-B). Observa-se na Figura 20, que o abrigo da UBS possui piso de concreto, paredes e teto de material resistente, estando de acordo com a legislação. No entanto, a Resolução exige portas com aberturas para ventilação, com tela de proteção contra acesso de vetores. Nesse caso, verifica-se que as portas com telas precisam ser reformadas, visto que $o$ abrigo possui quatro repartições e, somente em uma delas a porta está em boas condições. A falta de manutenção facilita a entrada de vetores e animais no ambiente, o que não é permitido pela Resolução. 
Figura 20 - Portas do abrigo externo da unidade com a tela de proteção

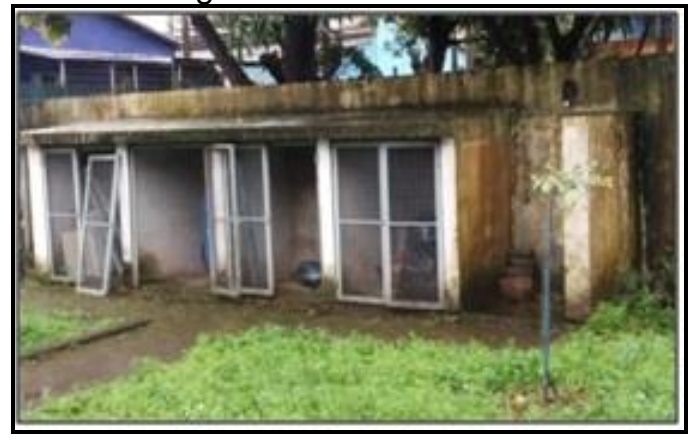

Fonte: Autora, 2019.

Outra condição que a Resolução exige, é a identificação, conforme os grupos dos RSS armazenados. Entretanto, nota-se nas Figuras 21-A e 21-B, a ausência desta identificação nas repartições do abrigo externo.

Figuras 21-A e 21-B - Ausência de identificação dos RSS no abrigo externo.

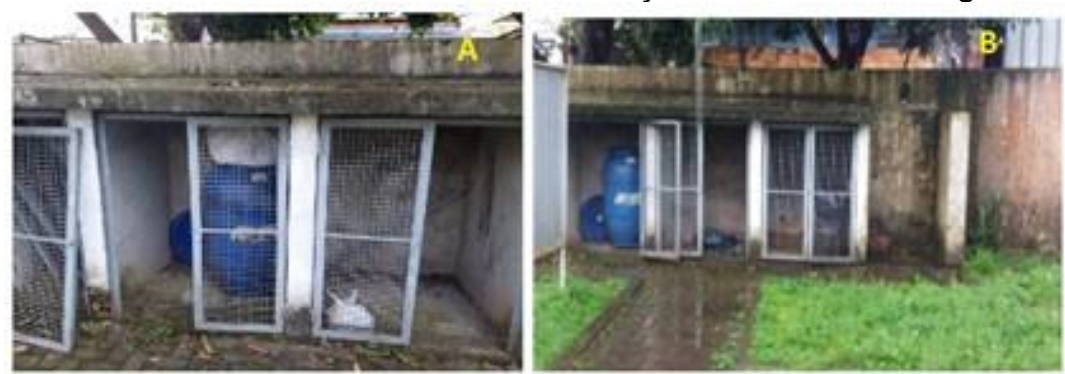

Fonte: Autora, 2019.

Além das exigências já mencionadas, a Resolução RDC N²22/2018, cita a necessidade de instalação de ponto de iluminação, para facilitar o processo de manejo dos RSS. Além da necessidade de área coberta com ponto de saída de água, para higienização e limpeza dos coletores utilizados, sendo estes, mais um dos itens que o abrigo externo da UBS não possui.

e) Coleta externa, tratamento e disposição final:

De acordo com a Resolução RDC N²22/2018 "a coleta externa consiste na retirada dos RSS do abrigo externo até a unidade de tratamento ou disposição final" (BRASIL, 2018-B). Ao realizar o diagnóstico na UBS, constatou-se que a coleta externa dos resíduos do serviço de saúde do Grupo A (infectante) e Grupo E (perfurocortante), são realizados uma vez por semana, por uma empresa terceirizada, a "MB Engenharia e Meio Ambiente LTDA", que encaminha para a 
empresa Stericycle realizar o tratamento e destinação final dos mesmos, ambas possuem licença de operação válida.

Os resíduos do Grupo B (químicos), não são coletados, porque os mesmos são descartados, após o uso, diretamente na rede de esgoto. A coleta dos resíduos pertencentes ao Grupo D (reciclável/comum) é realizada por uma cooperativa de reciclagem do município de Esteio/RS e pela Prefeitura do mesmo município, com periodicidade de recolhimento de duas vezes por semana. Quanto ao tratamento para os resíduos pertencentes aos Grupos A e E, o processo utilizado é a incineração realizada pela empresa licenciada. Já para os resíduos do Grupo D, não há tratamento. Os resíduos infectantes e perfurocortantes, após tratamento, são encaminhados para a destinação final, ou seja, um aterro sanitário no município de São Leopoldo/RS, assim como os resíduos comuns.

f) Gerenciamento dos grupos de resíduos do serviço de saúde:

Conforme o Art. $56^{\circ}$ da Resolução RDC comentada No 222/2018 "o gerenciamento dos RSS do Grupo B deve observar a periculosidade das substâncias presentes, decorrentes das características de inflamabilidade, corrosividade, reatividade e toxicidade" (BRASIL, 2018-C).

Ainda conforme a Resolução RDC comentada N 222/2018 Art. 58, "os RSS do Grupo B com características de periculosidade, no estado líquido, devem ser submetidos a tratamento antes da disposição final ambientalmente adequada" (BRASIL, 2018-C). Ao realizar o diagnóstico na UBS, constatou-se que são gerados resíduos químicos nos setores denominados "Sala de Enfermagem/ Ginecologia" e na "Sala de Odontologia". Os produtos químicos são utilizados para a realização de alguns procedimentos. Na "Sala de Enfermagem" os produtos químicos são utilizados para a realização de preventivos, ausculta dos batimentos cardíacos fetais, curativos, assepsia das mãos e do local. Já na "Sala de Odontologia" os produtos químicos utilizados são destinados para auxiliar na remoção e extração dentária, assepsia do local, e higienização das mãos.

Os produtos químicos usados no setor "Sala de Enfermagem" são: iodopovidona (PVPI), gel condutor, vaselina líquida e álcool diluído a 70\%, conforme apresentado nas Figuras 22-A e 22-B. 
Figuras 22-A e 22-B - Vista de alguns produtos Químicos utilizados na sala de enfermagem.
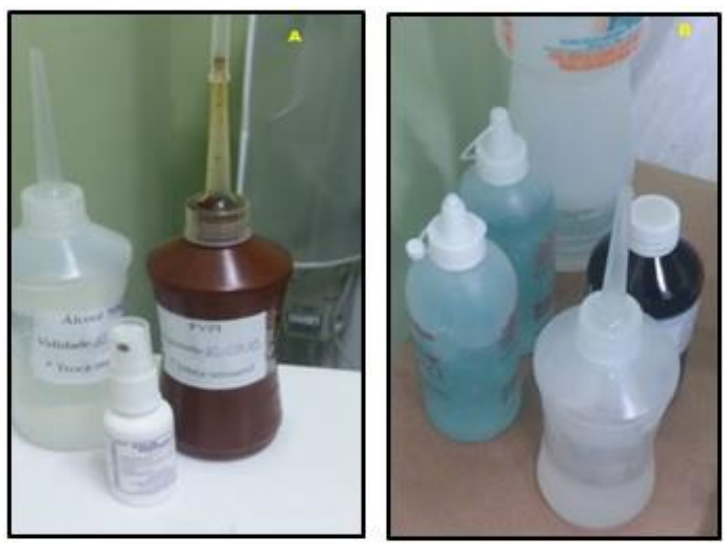

Fonte: Autora, 2019.

No setor "Sala de Odontologia" são usados os seguintes produtos químicos: resinas, flúor/gel, hipoclorito, formocresol, óxido de zinco e amálgama.

Foi possível verificar com o estudo realizado na UBS, que os resíduos destes produtos são lançados diretamente na rede de esgoto, quando substituídos semanalmente, ou seja, não possuem um gerenciamento adequado. Sendo que, a maioria desses produtos químicos usados nesses setores são classificados, segundo a norma ABNT NBR 10.004/2004 (ABNT, 2004) como resíduos Classe IPerigosos, pois apresentam propriedades como inflamabilidade, corrosividade, reatividade, toxicidade e patogenicidade.

De acordo com a Ficha de Informações de Segurança dos Produtos Químicos (FISPQ) esses produtos apresentam as seguintes características, quais sejam: álcool $70 \%$ é tóxico, reativo e inflamável; álcool em gel é inflamável e tóxico; gel condutor é inflamável, tóxico e reativo; iodopovidona e o hipoclorito são tóxicos e corrosivos; óxido de zinco é inflamável e reativo; amálgama e o formocresol são tóxicos. Nesse sentido, verifica-se que todos os produtos químicos utilizados nos procedimentos da UBS são classificados como Classe I- Perigosos e não poderiam ser lançados diretamente na rede de esgoto do município.

\section{g) Segurança Ocupacional:}

De acordo com o Art. 90 da Resolução RDC comentada N²22/2018, "a proteção à saúde e segurança dos trabalhadores nos estabelecimentos prestadores de serviços de saúde deve ser prioridade, sendo este, um item para o cumprimento das metas estabelecidas no PGRSS" (BRASIL, 2018-C). Ainda de acordo com a 
RDC comentada $\mathrm{N}^{\circ} 222 / 2018$, Art. 90, "o serviço deve garantir que os trabalhadores sejam avaliados periodicamente, atendendo a legislação específica, e mantendo registros desta avaliação". Esta medida é importante para proteger a saúde dos envolvidos no gerenciamento dos RSS (BRASIL, 2018-C). Na UBS, esta prática de avaliação periódica não é realizada, e não há registros para constar possíveis avaliações anteriores.

Além da avaliação periódica dos trabalhadores, conforme o Art. 91, o serviço deve manter um programa de educação continuada (permanente) para os trabalhadores e todos os envolvidos nas atividades de gerenciamento de resíduos, mesmo os que atuam temporariamente. Temas como "Sistema adotado para o gerenciamento dos RSS"; "Prática de segregação dos RSS"; "Símbolos, expressões, padrões de cores adotadas para o gerenciamento de RSS"; "Localização dos ambientes de armazenamento e dos abrigos de RSS" devem ser priorizados (BRASIL, 2018-C).

Ao realizar o diagnóstico na UBS, verificou-se a importância de ser ter um programa de educação voltado ao gerenciamento de resíduos, já que foram encontrados muitos equívocos referentes ao manejo dos mesmos. Alguns profissionais da UBS, foram questionados sobre a existência destes cursos de capacitação, onde a resposta de negação foi unânime. Para Meira (2016), a educação permanente é uma estratégia, uma oportunidade para o aprendizado e conhecimento, visando a conscientização da equipe, sendo dessa maneira, uma necessidade para os profissionais da área da saúde.

h) Análise dos registros da lista de verificação:

A partir dos registros constantes no instrumento "Lista de Verificação" (Check List), destacam-se, entre outras deficiências, que o gerenciamento dos resíduos na UBS, não abrange todas as etapas do planejamento dos recursos físicos, dos recursos materiais e da capacitação dos recursos humanos envolvidos. A Unidade não realiza a estimativa do RSS gerados por grupos. Além disso, não há procedimentos relacionados ao gerenciamento dos RSS quanto à geração, à segregação, ao acondicionamento, à identificação, à coleta, ao armazenamento, ao transporte, ao tratamento e à disposição final ambientalmente adequada. Salienta- 
se, ainda, que a Unidade não trabalha com seus fornecedores no sistema de logística reversa, conforme estabelecido pela Política Nacional dos Resíduos Sólidos em seu Art. 33 (BRASIL, 2010-A), o que reduziria o volume de resíduos gerados, principalmente de medicamentos vencidos e suas embalagens. Destacase, também, que a UBS não descreve as ações a serem adotadas em situações de emergência e acidentes decorrentes do gerenciamento dos RSS; não mantém registros de capacitação e treinamento dos funcionários envolvidos na prestação de serviço de limpeza. Também não mantém cópia do contrato de prestação de serviços e da licença ambiental das empresas prestadoras de serviços para a destinação dos RSS. Todas as falhas apontadas justificam-se pelo fato de que a UBS não elaborou o documento denominado "Plano de Gerenciamento de Resíduos do Serviço de Saúde (PGRSS), conforme determina o Art $5^{\circ}$ da Resolução RDC 222/2018.

\section{AÇÕES DE MELHORIA}

A partir da realização do diagnóstico dos resíduos gerados na UBS e da utilização do instrumento "Lista de Verificação" (Check List), com vistas a verificar o atendimento às exigências da Resolução RDC N²22/2018, várias deficiências na gestão dos resíduos puderam ser apontadas na UBS. Nesse sentido, cabe apontar ações para a melhoria e cumprimento da legislação vigente, como as que serão destacadas abaixo.

Serão apresentadas a seguir, as melhorias referentes ao gerenciamento de resíduos do serviço de saúde, que servirão como premissa para a implantação do Plano de Gerenciamento dos Resíduos do Serviço de Saúde (PGRSS) da Unidade, a fim de reduzir a possibilidade de ocorrência de incidentes e acidentes de trabalho, oriundos do manejo incorreto dos resíduos e minimizar os impactos ambientais negativos que estes podem causar. As seguintes ações de melhoria foram propostas, quais sejam:

-Elaborar o documento "Plano de Gerenciamento dos Resíduos do Serviço de Saúde (PGRSS)" da UBS;

-Criar uma comissão composta por funcionários dos diversos setores da UBS, que será responsável por elaborar o documento "Plano de Gerenciamento dos Resíduos 
do Serviço de Saúde (PGRSS)" atualizar o referido documento e ministrar treinamentos para as equipes; elaborar, atualizar e proporcionar treinamentos nos procedimentos internos de gestão de resíduos; programar e realizar auditorias internas nos diversos setores, utilizando como instrumento base o documento "Lista de Verificação" (Check List); propor ações de melhoria (ações corretivas) para as não conformidades detectadas durante a auditoria interna e trabalho rotineiro.

-Delegar a um funcionário, com competência técnica, a função de "Coordenador do Sistema de Gestão de Resíduos;

-Disponibilizar para o acondicionamento dos resíduos, recipientes providos de sistema de abertura com pedais, já que a prática manual é proibida pela Resolução RDC N²22/2018;

-Ampliar o local denominado "Sala de Expurgo", uma vez que a mesma abriga temporariamente os RSS. Atualmente, estes ficam dispostos diretamente no chão, prática pela Resolução RDC N²22/2018, que exige que os resíduos sejam depositados em bombonas e coletores;

-Identificar o local denominado "Sala de Expurgo", conforme exigência da Resolução RDC N²22/2018- Art. 29, como “ Abrigo Temporário de Resíduos"; -Identificar todos os coletores da UBS, com seus respectivos grupos de RSS, de forma clara e legível para auxiliar os profissionais na hora da segregação dos resíduos;

-Reformar o abrigo externo, colocando a identificação dos RSS, realizar manutenção nas portas de maneira a não facilitar a entrada de vetores e outros animais, colocar uma placa com a frase "Uso restrito aos funcionários", instalar iluminação e encanamento de água para facilitar a limpeza das bombonas e contêineres presentes no local;

-Instruir os profissionais responsáveis pela limpeza e coleta dos resíduos internos, sobre a importância do uso de EPIs, visto que estes funcionários não adotam, atualmente, o uso periódico dos mesmos;

-Elaborar procedimento interno para a identificação, segregação, tratamento e disposição final para os resíduos do Grupo B (Resíduos Químicos), já que estes são, atualmente, descartados diretamente na rede de esgoto do município de Esteio/RS; 
-Melhorar a prática de separação de resíduos do Grupo D (Resíduos Recicláveis e Comuns), visto que no município possui coleta seletiva, bem como cooperativa que recolhe os resíduos, sendo que, atualmente, a maioria dos resíduos gerados na UBS são misturados;

-Propor a utilização dos coletores com diferentes cores, conforme estabelecido pela Resolução CONAMA N²75/2001 (BRASIL, 2001), incentivando a coleta seletiva, já que na UBS existem os referidos coletores, no entanto, não estão situados em local estratégico de fácil visualização, motivo pelo qual são poucos usados por funcionários e pacientes.

\section{CONCLUSÃO}

Com o desenvolvimento deste trabalho pode-se perceber as deficiências do setor de saúde na gestão dos resíduos gerados. Verificou-se que é de suma importância que a UBS elabore o seu Plano de Gerenciamento dos Resíduos do Serviço de Saúde (PGRSS), respeitando às exigências estabelecidas pela Resolução RDC № 222/2018.

O diagnóstico realizado na Unidade, bem como a proposição das ações de melhoria (ações corretivas), servirão como uma etapa preliminar para a implantação do sistema de gestão dos resíduos.

Cabe ressaltar que para o sucesso do sistema de gestão de resíduos deve haver o envolvimento de todos os profissionais atuantes na UBS. Nesse sentido, é importante estabelecer uma comissão de gestão de resíduos e um responsável técnico, para elaboração, atualização e treinamento no PGRS, a definição das diretrizes para a gestão dos resíduos na UBS, programação das auditorias internas e estabelecimento de ações corretivas, com vistas a atingir a melhoria contínua.

\section{REFERÊNCIAS}

ALVES, S. B., Manejo de Resíduos de Serviços de Saúde na Atenção Básica. Goiânia, 2010. Disponível em:<https://ppgenf.fen.ufg.br/up/127/o/Sergiane_Bisinoto_Alves.pdf> Acesso em: 18 nov 2018. 
ASSOCIAÇÃO BRASILEIRA DE NORMAS TÉCNICAS. ABNT NBR 12809:2013 . Resíduos de serviços de saúde - Gerenciamento de resíduos de serviços de saúde intra estabelecimento. Disponível em:

<http://licenciamento.ibama.gov.br/Ferrovias/EF-

334_Ferrovia\%20de\%20Integra\%C3\%A7\%C3\%A30\%200este\%20Leste\%20-

\%20FIOL_2052-08/Relatorios\%20Semestrais/13\%20Relat\%C3\%B3rio\%20Semestral\%20-

\%20Jan-Jul-2017/13\%20Relat\%C3\%B3rio\%20Semestral\%20-\%20Jan-Jul-

2017/\%5B211\%5D-0829825_Anexo_3515_2017_SUAMB_ABNT_NBR_12809.pdf>

Acesso em: 05 out 2018.

BRASIL. Ministério do Meio Ambiente. Resíduos Sólidos. 2018-A. Disponível em: $<$ http://www.mma.gov.br/cidades-sustentaveis/residuos-solidos> Acesso em: 30 set 2018.

BRASIL. Presidência da República Casa Civil. Subchefia para Assuntos Jurídicos. Lei № 12.305, de 02 de agosto de 2010. Institui a Política Nacional de Resíduos Sólidos. Disponível em <http://www.planalto.gov.br/ccivil_03/_Ato20072010/2010/Lei/L12305.htm > Acesso em: 27 nov de2018.

BRASIL. Presidência da República Casa Civil. Subchefia para Assuntos Jurídicos. Lei № 12.305, de 02 de agosto de 2010. Institui a Política Nacional de Resíduos Sólidos. Disponível em <http://www.planalto.gov.br/ccivil_03/_Ato20072010/2010/Lei/L12305.htm> Acesso em: 27 nov de2018.

BRASIL. Presidência da República Casa Civil. Subchefia para Assuntos Jurídicos. Decreto $\mathbf{N}^{\circ}$ 7.404, de 23 de dezembro de 2010. Regulamenta a Lei $\mathrm{N}^{\circ} 12.305$, de 02 de agosto de 2010 que institui a Política Nacional de Resíduos Sólidos.

Disponível em < http://www.planalto.gov.br/ccivil_03/Ato20072010/2010/Decreto/D7404.htm> Acesso em: 27 nov de2018.

BRASIL. Ministério do Meio Ambiente, Conselho Nacional de Meio Ambiente, CONAMA. Resolução CONAMA № 01, de 23 de janeiro de 1986. Dispõe sobre critérios básicos e diretrizes gerais para a avaliação de impacto ambiental.

Disponível em:

$<$ http://www2.mma.gov.br/port/conama/legislacao/CONAMA_RES_CONS_1986_00 1.pdf>Acesso em: 05 out. 2018.

BRASIL. Ministério do Meio Ambiente, Conselho Nacional de Meio Ambiente, CONAMA. Resolução CONAMA № 275, de 25 de abril de 2001. Estabelece o código de cores para os diferentes tipos de resíduos, a ser adotado na identificação de coletores e transportadores, bem como nas campanhas informativas para a coleta seletiva. Disponível em: < http://www2.mma.gov.br/port/conama/legislacao/CONAMA_RES_CONS_2001_275. pdf>

Acesso em: 27 nov 2018.

BRASIL. NR 32 - Segurança e saúde no trabalho em serviços de saúde. Portaria Ministério de Trabalho e Emprego - MTE № 485, de 11 de novembro de 2005 (DOU

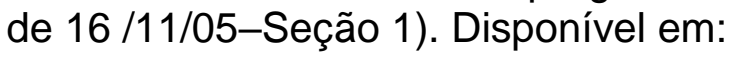


<http://www.fiocruz.br/biosseguranca/Bis/manuais/legislacao/NR-32.pdf > Acesso em: 07 out. 2018.

BRASIL. Resolução da Diretoria Colegiada № 306 de 07 de dezembro de 2004. Dispõe sobre o Regulamento Técnico para o Gerenciamento de Resíduos de Serviços de Saúde. Disponível em:

<http://portal.anvisa.gov.br/documents/33880/2568070/res0306_07_12_2004.pdf/95 eac678-d441-4033-a5ab-f0276d56aaa6> Acesso em: 20 set 2018.

BRASIL. Resolução da Diretoria Colegiada № 222, de 28 de março de 2018. Regulamenta as Boas Práticas de Gerenciamento dos Resíduos de Serviços de Saúde e dá Outras Providências. 2018-B. Disponível em:

<http://portal.anvisa.gov.br/documents/10181/3427425/RDC_222_2018_.pdf/c5d308 1d-b331-4626-8448-c9aa426ec410> Acesso em 21 set 2018.

BRASIL. Resolução da Diretoria Colegiada № 222/2018, de 21 de março de 2018. Comentada. Gerência de Regulamentação e controle sanitário em serviços de saúde - GRECS/Gerência Geral de Tecnologia em Serviços de Saúde GGTES/ANVISA. 2018-C Disponível em: <http://portal.anvisa.gov.br/documents/33852/271855/RDC+222+de+Mar\%C3\%A7o +de+2018+COMENTADA/edd85795-17a2-4e1e-99ac-df6bad1e00ce> Acesso em 20 set 2018.

BRASIL. Ministério da Saúde. Agência Nacional de Vigilância Sanitária. Manual de gerenciamento de resíduos de serviços de saúde. Brasília, 2006. (Série A. Normas e Manuais Técnicos). Disponível em: <http://bvsms.saude.gov.br/bvs/publicacoes/manual_gerenciamento_residuos.pdf> Acesso em: 03 nov 2018.

BRASIL. Ministério da Saúde. Departamento de Atenção Básica. Estratégia Saúde da Família. 2018-D. Disponível em:

<http://dab.saude.gov.br/portaldab/ape_esf.php> Acesso em: 11 out 2018.

BRASIL. Ministério da Saúde. Módulo 5. Controle de Resíduos de Serviços de Saúde. BRASÍLIA DF 2002. Disponível em:<http://bvsms.saude.gov.br/bvs/publicacoes/UNIDADE05.PDF> Acesso em: 15 out 2018.

De PAIVA, L. H. Hospital de Clínicas da Universidade Federal do Triângulo Mineiro Administrado pela empresa brasileira de serviços hospitalares (EBSERH). Plano de Gerenciamento de Resíduos de Serviços de Saúde. Versão 2.0, de 03/2018. Disponível em:<http://www.ebserh.gov.br/documents/147715/0/PGRSS+3.pdf/c504ff37-f3bc4a09-a7d1-560fd006d1b8> Acesso em 19 out 2018.

IBGE. Instituto Brasileiro de Geografia e Estatística. Panorama Esteio. Disponível em: <https://cidades.ibge.gov.br/brasil/rs/esteio/panorama> Acesso em 09 out 2018. 
MOREIRA, A. M.M.; GÜNTHER, W. M. R. Gerenciamento de resíduos sólidos em unidades básicas de saúde: aplicação de instrumento facilitador. Solid waste management in primary healthcare centers: application of a facilitation tool. Rev. Latino-Am. Enfermagem. 2016; Rev. Latino-Am. Enfermagem vol.24 Ribeirao Preto 2016. Disponível em: <http://www.scielo.br/pdf/rlae/v24/pt_0104-1169-rlae24-02768.pdf> Acesso em 28 out 2018.

MEIRA, S. R. C. Educação Permanente Na Gestão De Resíduos Em Hospital Universitário. Disponível em:

<http://portal.anvisa.gov.br/documents/33852/271855/RDC+222+de+Mar\%C3\%A7o +de+2018+COMENTADA/edd85795-17a2-4e1e-99ac-df6bad1e00ce> Acesso em 17 nov 2018.

SILVA, L. E. S. S. S; De OLIVEIRA, J. S. B.; EVANGELISTA, T. J.; Suto, C. S. S.; MASCARENHAS, N. B. Gerenciamento dos resíduos de serviços de saúde: atenção básica e hospitalar. Rev. Gestão \& Saúde (Brasília) Vol. 08, n. 02, maio. 2017. p 318-337. Disponível em:<http://periodicos.unb.br/ojs311/index.php/rgs/article/download/3730/3406/> Acesso em: 06 out 2018.

SILVA, C. R.; RODRIGUES, M. S. Proposta de gestão de resíduos de produtos químicos gerados nas unidades públicas de saúde no município de Viamão (RS). Disponível em:

$<$ https://periodicos.ifrs.edu.br/index.php/ScientiaTec/article/download/2132/pdf > Acesso em 19 nov 2018.

SILVA, T. B. Resíduos Sólidos: Lei 12.305/2010: Política Nacional dos Resíduos Sólidos Comentada artigo por artigo. São Paulo /SP: Editora Nova Onda EIRELI-ME,2016.

SOUZA, R. M. G. L. et al. Gerenciamento dos Resíduos de Serviços de Saúde. Editora ANVISA. Brasília, 2006. Disponível em:

$<$ http://www.anvisa.gov.br/servicosaude/manuais/manual_gerenciamento_residuos. pdf> Acesso em: 02 out 2018.

TAKADA, S.C.A. O Plano de Gerenciamento de Resíduos de Serviços de Saúde e o Direito do Trabalhador. Disponível em: $<$ http://www.bvsde.paho.org/bvsacd/cd49/agda.pdf> Acesso em: 21 set 2018. 